Published in final edited form as:

J Am Chem Soc. 2020 February 05; 142(5): 2264-2276. doi:10.1021/jacs.9b09616.

\title{
Electronic Structures and Reactivity Profiles of Aryl Nitrenoid- Bridged Dicopper Complexes
}

\author{
Kurtis M. Carsch, \\ Department of Chemistry and Chemical Biology, Harvard University, Cambridge, Massachusetts \\ 02138, United States \\ James T. Lukens, \\ Department of Chemistry and Chemical Biology, Baker Laboratory, Cornell University, Ithaca, \\ New York 14853, United States
}

Ida M. DiMucci, Department of Chemistry and Chemical Biology, Baker Laboratory, Cornell University, Ithaca, New York 14853, United States

Diana A. lovan, Department of Chemistry and Chemical Biology, Harvard University, Cambridge, Massachusetts 02138, United States

\section{Shao-Liang Zheng,}

Department of Chemistry and Chemical Biology, Harvard University, Cambridge, Massachusetts 02138, United States

\section{Kyle M. Lancaster ${ }^{*}$,}

Department of Chemistry and Chemical Biology, Baker Laboratory, Cornell University, Ithaca, New York 14853, United States

\section{Theodore A. Betley ${ }^{*}$}

Department of Chemistry and Chemical Biology, Harvard University, Cambridge, Massachusetts 02138, United States

\section{Abstract}

Dicopper complexes templated by dinucleating, pacman dipyrrin ligand scaffolds ( ${ }^{\mathrm{Mes}} \mathrm{dmx}$, ${ }^{t B u} \mathrm{dmx}$ : dimethylxan-thine-bridged, cofacial bis-dipyrrin) were synthesized by deprotonation/ metalation with mesitylcopper (CuMes; Mes: mesityl) or by transmetalation with cuprous precursors from the corresponding deprotonated ligand. Neutral imide complexes $\left({ }^{\mathrm{R}} \mathrm{dmx}\right) \mathrm{Cu}_{2}\left(\mu^{2}\right.$ NAr) (R: Mes, ${ }^{t} \mathrm{Bu}$; Ar: 4- $\left.\mathrm{MeOC}_{6} \mathrm{H}_{4}, 3,5-\left(\mathrm{F}_{3} \mathrm{C}\right)_{2} \mathrm{C}_{6} \mathrm{H}_{3}\right)$ were synthesized by treatment of the corresponding dicuprous complexes with aryl azides. While one-electron reduction of

\footnotetext{
*Corresponding Authors kml236@cornell.edu; betley@ chemistry.harvard.edu. Supporting Information

The Supporting Information is available free of charge at https://pubs.acs.org/doi/10.1021/jacs.9b09616.

Synthesis of 1-18, spectroscopic characterization, computational details, CheckCIF results, solid-state molecular structures, and supplementary spectra (PDF)

Model of the $\left(\mathrm{R}_{\mathrm{dmx}}\right) \mathrm{Cu}_{2}\left(\mu^{2}-\mathrm{NAr}\right)$ complex (CIF)

The authors declare no competing financial interest.
} 
$\left.{ }^{\mathrm{Mes}} \mathrm{dmx}\right) \mathrm{Cu}_{2}\left(\mu^{2}-\mathrm{N}\left(\mathrm{C}_{6} \mathrm{H}_{4} \mathrm{OMe}\right)\right)$ with potassium graphite initiates an intramolecular, benzylic

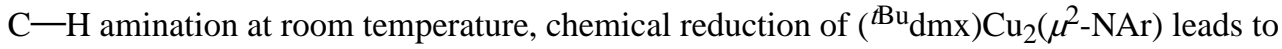
isolable $\left[\left({ }^{t B u} \mathrm{dmx}\right) \mathrm{Cu}_{2}\left(\mu^{2}-\mathrm{NAr}\right)\right]^{-}$product salts. The electronic structures of the thermally robust $\left[\left({ }^{\left({ }^{B u} \mathrm{dmx}\right.}\right) \mathrm{Cu}_{2}\left(\mu^{2}-\mathrm{NAr}\right)\right]^{0 /-}$ complexes were assessed by variable-temperature electron paramagnetic resonance spectroscopy, X-ray absorption spectroscopy $\left(\mathrm{Cu} \mathrm{L}_{2,3} / \mathrm{K}\right.$-edge, $\mathrm{N} \mathrm{K}$ edge), optical spectroscopy, and DFT/CASSCF calculations. These data indicate that the formally Class IIIA mixed valence complexes of the type $\left[\left({ }^{R} \mathrm{dmx}\right) \mathrm{Cu}_{2}\left(\mu^{2}-\mathrm{NAr}\right)\right]^{-}$feature significant NArlocalized spin following reduction from electronic population of the $\left[\mathrm{Cu}_{2}\left(\mu^{2}-\mathrm{NAr}\right)\right] \pi^{*}$ manifold, contrasting previous methods for engendering iminyl character through chemical oxidation. The reactivity of the isolable imido and iminyl complexes are examined for prototypical radicalpromoted reactivity (e.g., nitrene transfer and $\mathrm{H}$-atom abstraction), where the divergent reactivity is rationalized by the relative degree of $\mathrm{N}$-radical character afforded from different aryl substituents.

\section{Graphical Abstract}

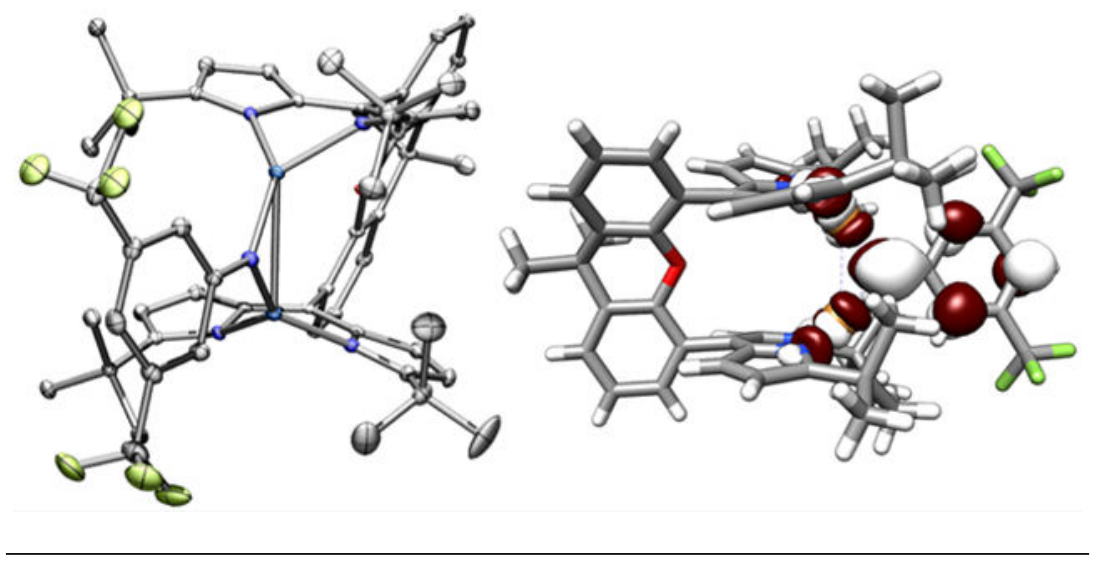

\section{INTRODUCTION}

The incorporation of heteroatom functionality into unactivated $\mathrm{C}-\mathrm{H}$ bonds remains a paramount challenge in both fine chemical synthesis and the conversion of hydrocarbon feedstocks into commodity chemicals. ${ }^{1-4}$ Dicopper complexes featuring bridging imido or oxo moieties have been implicated in the amination and hydroxylation of aliphatic $\mathrm{C}-\mathrm{H}$ bonds, albeit by two distinct mechanisms. The dicopper imido complexes reported by Warren and co-workers are proposed to be in equilibrium with a mononuclear copper complex and a terminal copper nitrenoid species, to which the latter is attributed for the observed $\mathrm{C}-\mathrm{H}$ bond amination reactivity (Figure 1) ${ }^{5-8}$ Steric profile tuning of the ancillary ligands for both $\beta$-diketiminate and dipyrrin platforms allowed for observation of reductively coupled terminal nitrenoid complexes ${ }^{8}$ as well as the isolation of authentic terminal copper nitrene complexes, ${ }^{9}$ respectively. The amination reactivity can be contrasted with the partial hydroxylation of methane to methanol by zeolite $\mathrm{Cu}-\mathrm{ZSM}-5,{ }^{10}$ ascribed to a bent, dicupric oxide core (Figure 1). ${ }^{11}$ The bent geometry of the zeoliteconfined $\mathrm{Cu}_{2}{ }_{2}\left(\mu^{2}-\mathrm{O}\right)$ core has been proposed to endow oxylcharacter on the oxenoid fragment in the transition state, facilitating low-barrier $\mathrm{H}$-atom abstraction and radical recombination yielding methanol. ${ }^{12}$ We were thus interested in synthesizing dicopper coordination complexes featuring bridging moieties 
to establish rigorous electronic structure to reactivity correlations. More specifically, we seek to probe how redox changes to a $\left[\mathrm{Cu}_{2}\left(\mu^{2}-\mathrm{E}\right)\right]^{n}$ core can induce spin accumulation at the bridgehead ligand, promote radical reactivity across the $\mathrm{Cu}-\mathrm{E}$ bond vector, and achieve substrate functionalization.

To correlate the electronic structures with the reactivity profiles of bimetallic transition metal complexes, we have prepared a dinucleating, dimethylxanthene-tethered, bis(dipyrrin) ligand scaffold which proximally orients two metals cofacially to facilitate multielectron chemistry. These architectures are well suited to stabilize bridged transition metal species as evidenced by the isolation of bridging ferrous oxo and hydroxo complexes. ${ }^{13}$ Furthermore, we hypothesize a semirigid spacer minimizes entropic penalties and promotes a dinuclear arrangement for the exploration of dinuclear bridging complexes across distinct redox states. These design principles are prevalent in tethered diiron porphyrin complexes, ${ }^{14-16}$ competent for catalytic hydroxylation of exogenous substrates upon photolysis. In addition, the dipyrrin scaffold limits access to the primary coordination sphere, rendering the metal ions high-spin and electrophilic. ${ }^{17-19}$

In this study, we examine nitrene group transfer to a dicopper core. The electronic structure and reactivity profile of the $\left[\mathrm{Cu}_{2}\left(\mu^{2}-\mathrm{NR}\right)\right]$ core is assessed as a function of redox state. Notably, we observe that one-electron reduction of the neutral $\left[\mathrm{Cu}_{2}\left(\mu^{2}-\mathrm{NR}\right)\right]$ complex induces spin accumulation at the bridging nitrenoid fragment (Figure 1), leading to a diagnostic iminyl signature via $\mathrm{N}$ K-edge spectroscopy that is indistinguishable from subvalent iminyl agents generated from oxidation of the metal imido precursors. The reactivity profiles of both the neutral and anionic $\left[\mathrm{Cu}_{2}\left(\mu^{2}-\mathrm{NR}\right)\right]$ complexes are assessed in the contexts of nitrene transfer to nucleophiles and propensity for $\mathrm{H}$-atom abstraction, with divergent pathways as a function of the aryl substituent attributable to varying degrees of radical character at the nitrenoid bridgehead.

\section{RESULTS}

\subsection{Synthesis of Dinuclear Dicopper Imido Complexes.}

Synthesis of the mesityl-flanked, cofacial bis(dipyrrin) ligand featuring a dimethylxanthene spacer $\left({ }^{\mathrm{Mes}} \mathrm{dmx}\right) \mathrm{H}_{2}$ was modified from the procedure to prepare the reported $\left({ }^{(B \mathrm{Bu}} \mathrm{dmx}\right) \mathrm{H}_{2}$ analogue (see the Supporting Information for experimental details). ${ }^{13}$ Acid-catalyzed condensation of 2-mesityl-1 $H$-pyrrole ${ }^{20}$ with dimethylxanthene bis(aldehyde), ${ }^{21}$ followed by oxidation of the bis(dipyrromethane) with excess 2,3-dichloro-5,6-dicyano-1,4benzoquinone (DDQ, 3.0 equiv) afforded ( $\left.{ }^{\mathrm{Mes}} \mathrm{dmx}\right) \mathrm{H}_{2}$ in excellent yield (79\%) on multigram scales as a red-orange powder. Under an atmosphere of nitrogen, $\left({ }^{\mathrm{Mes}} \mathrm{dmx}\right) \mathrm{H}_{2}$ was deprotonated with mesitylcopper ${ }^{22}$ in a thawing benzene/acetonitrile solvent mixture (20:1, 10 equiv. acetonitrile) to afford ( $\left.{ }^{\mathrm{Mes}} \mathrm{dmx}\right) \mathrm{Cu}_{2}(\mathrm{NCMe})_{2}$ (l) as a red-pink powder (Scheme 1). Trituration of the crude reaction mixture with cold acetonitrile precipitated $\mathbf{1}$ in analytically pure form (82\%). Single crystals of $\mathbf{1}$ suitable for X-ray diffraction were prepared by layering acetonitrile with a concentrated diethyl ether solution of $\mathbf{1}$ at $-35^{\circ} \mathrm{C}$ overnight. The solid-state structure displays a large copper—copper distance (6.3800(7) $\AA$ ) and noncofacial arrangement $\left(28.7(1)^{\circ}\right.$ distortion with respect to the dipyrrin planes), 
suggesting no intramolecular communication between individual Cu-dipyrrin units (Figure S-73).

Heating a benzene solution of 1 with a minor excess (1.2 equiv) of 4-methoxyphenyl azide (4- $\left.\mathrm{MeOC}_{6} \mathrm{H}_{4} \mathrm{~N}_{3}\right)$ or 3,5-bis(trifluoromethyl)phenyl azide $\left(3,5-\left(\mathrm{F}_{3} \mathrm{C}_{2} \mathrm{C}_{6} \mathrm{H}_{3} \mathrm{~N}_{3} ; 45^{\circ} \mathrm{C}, 16 \mathrm{~h}\right.\right.$ ) afforded the dicopper imido complexes $\left({ }^{\mathrm{Mes}} \mathrm{dmx}\right) \mathrm{Cu}_{2}\left(\mu^{2}-\mathrm{N}\left(\mathrm{C}_{6} \mathrm{H}_{4} \mathrm{OMe}\right)\right)(2)$ and $\left({ }^{\mathrm{Mes}} \mathrm{dmx}\right) \mathrm{Cu}_{2}\left(\mu^{2}-\mathrm{N}\left(3,5-\left(\mathrm{F}_{3} \mathrm{C}\right)_{2} \mathrm{C}_{6} \mathrm{H}_{3}\right)\right)(3)$, respectively (Scheme 2$)$. Both reactions were accompanied by gradual effervescence with a marked color change from red-pink (1) to deep violet (2) or purplepink (3). Trituration of imido complexes $\mathbf{2}$ and $\mathbf{3}$ with cold acetonitrile allowed for isolation of analytically pure products after filtration in excellent yields (2: 92\%, 3: 79\%). The diamagnetic ${ }^{1} \mathrm{H}$ NMR spectra, satisfactory elemental analyses, and featureless perpendicular-mode EPR spectra indicate an overall singlet spin ground state and establish bulk purity for $\mathbf{2}$ and $\mathbf{3}$ (Figure S-7, S-9).

The solid-state structures of $\mathbf{2}$ and $\mathbf{3}$ (Figures 2a and S-75) determined by single crystal Xray diffraction reveal contractions of the copper—copper distances (2: 2.822(1) $\AA$, $\mathbf{3}$ : $2.844(1) \AA$ ) as compared to $\mathbf{1}(6.3800(7) \AA)$. These bond metrics are comparable to the geometric sum of the van der Waals radii (approximately $1.40 \AA)^{23}$ and nearly $0.10 \AA$ shorter than reported dinuclear copper imido complexes (Table 1) . $^{5-7,24}$ This geometric contraction results in a more cofacial arrangement of the dipyrrin units $\left(2: 6.7(1)^{\circ}\right.$ torsion, $\mathbf{3}$ :

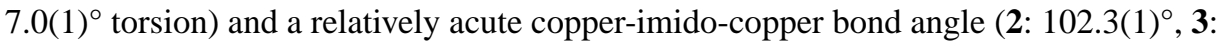
103.1 $\left.(2)^{\circ}\right)$. The displacement of the copper centers with respect to the dipyrrin plane ( 2 : 0.879(6) $\AA, 0.854(5) \AA$; 3: 0.848(3) $\AA, 0.848(3) \AA$ ) compared to 1 (0.242(4) $\AA, 0.407(3) \AA$ ) reflects the capability of the tethered bis(dipyrrin) ligand platform to support diverse intermetallic distances.

We also explored how modifications of the dipyrrin flanking units influence the resulting $\left[\mathrm{Cu}_{2}\right]$ core properties. In contrast to metalation of the $\left({ }^{\mathrm{Mes}} \mathrm{dmx}\right) \mathrm{H}_{2}$ platform, metalation of $\left({ }^{(B \mathrm{Bu}} \mathrm{dmx}\right) \mathrm{H}_{2}$ in the presence of coordinating solvents with mesitylcopper did not furnish the desired bis(cuprous) synthon. Consequently, an alternative transmetalation protocol was pursued. Exposure of $\left({ }^{(B \mathrm{Bu}} \mathrm{dmx}\right) \mathrm{H}_{2}$ in benzene to potassium bis(trimethylsilyl)amide (2.1 equiv) rapidly precipitated an insoluble orange powder, which was isolated by filtration and rinsed with boiling toluene to furnish the putative dianionic $\left[\left({ }^{t B u} \mathrm{dmx}\right) \mathrm{K}_{2}\right](\mathbf{4})$. Due to the insolubility of $\mathbf{4}$ in organic media, $\mathbf{4}$ was not structurally characterized and used without further purification. Treatment of $\mathbf{4}$ as a suspension in tetrahydrofuran with excess copper bromide dimethylsulfide (2.2 equiv) followed by addition of excess aryl azide (1.8 equiv.; 4$\mathrm{MeOC}_{6} \mathrm{H}_{4} \mathrm{~N}_{3}$ or, 3,5- $\left.\left(\mathrm{F}_{3} \mathrm{C}\right)_{2} \mathrm{C}_{6} \mathrm{H}_{3} \mathrm{~N}_{3} ; 75{ }^{\circ} \mathrm{C}, 16 \mathrm{~h}\right)$ afforded the corresponding imido

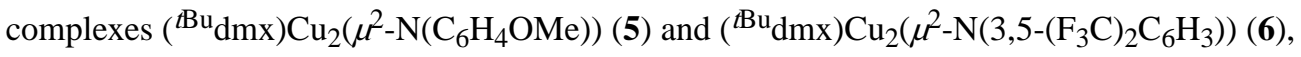
respectively, as deep purple solids (Scheme 3 ). Both products were isolated by filtration in cold acetonitrile and recrystallized from a saturated acetonitrile/diethyl ether solution at -35 ${ }^{\circ} \mathrm{C}$ in moderate yield (5: 65\%, 6: 49\%). Single crystal X-ray diffraction reveals short copper-copper distances (5: 2.837(1) $\AA$, 6: 2.875(1) $\AA$ ) akin to those of $\mathbf{2}$ and $\mathbf{3}$ (Figures 2b and S-76 and Table 1). 


\subsection{Redox Chemistry of $\left[\mathrm{Cu}_{2}\left(\mu^{2}-\mathrm{NR}\right)\right]$.}

To assess the redox properties of the dicopper imido complexes, we collected cyclic voltammetry $(\mathrm{CV})$ on imido complexes $\mathbf{2}, \mathbf{3}, \mathbf{5}$, and $\mathbf{6}$ in tetrahydrofuran $(0.01 \mathrm{mM}$ substrate, $\left.0.2 \mathrm{M}\left[{ }^{n} \mathrm{Bu}_{4} \mathrm{~N}\right]\left[\mathrm{PF}_{6}\right]\right)$. One quasi-reversible reduction was observed at moderate potentials for both $p$-OMe substituted imidos $\left(2:-1.32 \mathrm{~V}, \mathbf{5}:-1.18 \mathrm{~V}\right.$ vs $\left[\mathrm{Cp}_{2} \mathrm{Fe}\right]^{+/ 0}$, Figure S-61), indicating the $\left[\mathrm{Cu}_{2}\left(\mu^{2}-\mathrm{NAr}\right)\right]$ core could be chemically reduced. Imido complexes $\mathbf{3}$ and $\mathbf{6}$ similarly reveal quasi-reversible reductive processes at milder potentials consistent with the imido electron withdrawing substituents $\left(3:-0.95 \mathrm{~V}, \mathbf{6}:-0.70 \mathrm{~V}\right.$ vs $\left[\mathrm{Cp}_{2} \mathrm{Fe}\right]^{+/ 0}$, Figure S-61). Accordingly, treatment of $\mathbf{2 , 5}$, or $\mathbf{6}$ in thawing tetrahydrofuran with stoichiometric potassium graphite $\left(\mathrm{KC}_{8}\right)$ in the presence of Cryptand $222\left(\mathrm{C}_{222}, 1.2\right.$ equiv) precipitated insoluble graphite and furnished a rapid color change from deep purple to brown-pink $(\mathbf{2}, \mathbf{5})$ or brown-orange (6; Scheme 4). For the reduction product of $\mathbf{2}$, an isolated yield could not be obtained due to the thermal instability of the product (vide infra); nonetheless, rapid addition of stoichiometric silver trifluoromethanesulfonate (AgOTf) in situ following $\mathrm{KC}_{8}$ addition at low temperature afforded quantitative recovery of $\mathbf{2}$ with deposition of metallic silver, suggesting the single-electron reduction proceeds in quantitative yield to a new paramagnetic species. Single-crystals of 7 suitable for X-ray diffraction were obtained by layering the crude reduction reaction of $\mathbf{2}$ in tetrahydrofuran with a thawing benzene/ hexanes mixture at $-35{ }^{\circ} \mathrm{C}$, ensuring all manipulations were conducted at cryogenic temperatures (see the Supporting Information for experimental details). Identification of the brown-pink crystals by single crystal $\mathrm{X}$-ray diffraction revealed the monoanionic bimetallic copper imido complex, [K( $\left.\left.\mathrm{C}_{222}\right)\right]\left[\left({ }^{\mathrm{Mes}} \mathrm{dmx}\right) \mathrm{Cu}_{2}\left(\mu^{2}-\mathrm{N}\left(\mathrm{C}_{6} \mathrm{H}_{4} \mathrm{OMe}\right)\right)\right]$ (7; Figure 3a). Similarly, bulk recrystallization of the reduction of 5 and $\mathbf{6}$ with stoichiometric $\mathrm{KC}_{8}$ in the presence of $\mathrm{C}_{222}$ from a tetrahydrofuran/diethyl ether solution layering at $-35^{\circ} \mathrm{C}$ afforded large crystals of $\left[\mathrm{K}\left(\mathrm{C}_{222}\right)\right]\left[\left({ }^{\mathrm{Bu}} \mathrm{dmx}\right) \mathrm{Cu}_{2}\left(\mu^{2}-\mathrm{NAr}\right)\right]\left(\mathrm{Ar}: 4-\mathrm{MeOC}_{6} \mathrm{H}_{4}, \mathbf{8} ; 3,5-\left(\mathrm{F}_{3} \mathrm{C}\right)_{2} \mathrm{C}_{6} \mathrm{H}_{3}, \mathbf{9}\right)$. Unlike thermally sensitive $\mathbf{7}$, anions 8 and $\mathbf{9}$ persist in solution at room temperature over several days.

Single crystal X-ray diffraction confirmed the composition of anionic imido complexes 7-9, representative structures of which are provided in Figure 3 for $\mathbf{7}$ and $\mathbf{9}$. All three anionic complexes display elongation of the $\mathrm{Cu}-\mathrm{N}_{\text {imide }}$ bonds (average, $\AA$, 2: 1.812(4), 7: 1.850(3); 5: 1.822(7), 8: 1.865(2); and 6: 1.824(8), 9: 1.857(2), all relevant bond lengths are provided in Table 1). Complexes 7 and 9 display elongated $\mathrm{Cu}-\mathrm{Cu}$ bonds (7: 2.9031(7) $\AA$; 9 : 2.8401(5) $\AA$ ) whereas 8 reveals a $\mathrm{Cu}-\mathrm{Cu}$ bond contraction $(8: 2.9448(7) \AA)$. The reduction similarity proceeds with elongation of the dipyrrin-copper bond lengths (average, $\AA$, 2 : 1.942(4), 7: 2.007(3); 5: 1.952(8), 8: 2.019(2); and 6: 1.939(8), 9: 2.005(2)), in accord with more electron-rich $\mathrm{Cu}$ ion. Further bond metrics analysis reveals a contraction of the $\mathrm{N}_{\mathrm{imide}}-\mathrm{C}_{\mathrm{ispo}}$ bond (average, $\AA$, 2: 1.375(6), 7: 1.318(4); 5: 1.383(10), 8: 1.351(3); and 6: 1.386(12), 9: 1.342(3)) and elongation of the $\mathrm{C}_{\mathrm{ipso}}-\mathrm{C}_{\text {ortho }}$ bond (average/ $\mathrm{A}, 2: 1.415(7), 7$ : 1.433(5); 5: 1.397(12), 8: 1.427(3); and 6: 1.407(13), 9: 1.428(4)).

$\mathrm{X}$-band electron paramagnetic resonance (EPR) spectroscopy on a thawing 2methyltetrahydrofuran solution of $\mathbf{7}$ displays a seven-line pattern, which was appropriately modeled with predominant isotropic copper hyperfine coupling $\left({ }^{63} \mathrm{Cu}_{2} A_{\text {iso }}=87.4 \mathrm{MHz}\right)$ and a minor contribution from nitrogen hyperfine coupling $\left({ }^{14} \mathrm{~N} \mathrm{~A}_{\text {iso }}=17.8 \mathrm{MHz}\right.$ ) (Figure 
4a). At lower temperatures ( $4 \mathrm{~K}$ ), the hyperfine coupling becomes anisotropic with copper hyperfine coupling values ${ }^{63} \mathrm{Cu}_{2} A_{X}=9.3 \mathrm{MHz}, A_{y}=43.9 \mathrm{MHz}$, and $A_{z}=9.7 \mathrm{MHz}$ and ${ }^{14} \mathrm{~N}$ $A_{X}=86.6 \mathrm{MHz}, A_{y}=125.6 \mathrm{MHz}$, and $A_{z}=130.3 \mathrm{MHz}$ (Figure 5b). Akin to 7, EPR spectra of both 8 and 9 are indicative of an $S=1 / 2$ spin ground state which display seven-line patterns at room temperature in 2-methyltetrahydrofuran (Figure S-21 for 8 and S-24 for 9). The large anisotropic nitrogen hyperfine coupling resolved at low temperatures (Figure S-22 for 8 and S-25 for 9 ) is consistent with a significant contribution of the $\mathrm{N} 2 \mathrm{p}_{X}$ orbital to the now singly occupied redox active molecular orbital (vida infra). Absorptions of near-infrared wavelengths (1000-2000 nm) were detected for both the neutral $(\mathbf{5 , 6})$ and anionic $(\mathbf{8 , 9})$. This largely precludes assignment of any of these NIR bands as intervalence charge transfer (Figure S-60). This assertion is supported by TDDFT calculations, as no bands in the NIR or visible region present as intervalence charge transfer bands (IVCT; Figure S-72 and Table $\mathrm{S}-1$ ). Moreover, variable temperature UV-vis absorption measurements on 8 in 2 methyltetrahydrofuran indicate no substantial electronic rearrangements as a function of temperature (Figure S-59).

\subsection{X-ray Absorption Spectroscopy.}

Multiedge X-ray absorption near edge structure (XANES) spectroscopy comprising $\mathrm{Cu}$ Kedge, $\mathrm{Cu} \mathrm{L}_{2,3}$-edge, and $\mathrm{N} \mathrm{K}$-edge measurements were carried out to probe and differentiate the electronic structures of neutral 5, 6 and anionic 8, 9. Cuprous $\left({ }^{(\mathrm{Bu}} \mathrm{L}\right) \mathrm{Cu}(\mathrm{NCMe})(\mathbf{1 0})$ and cupric $\left[\left({ }^{\mathrm{Bu}} \mathrm{L}\right) \mathrm{CuCl}\right]_{2}(\mathbf{1 1})$ complexes were prepared and measured as reference dipyrrinsupported copper complexes. Previously, Lancaster and co-workers illustrated that high energy Cu K-edge pre-edge features $(\sim 8981 \pm 0.5 \mathrm{eV})$, typically assigned as $\mathrm{Cu} 1 s \rightarrow 3 d$ excitations, can instead be indicative of a ligand-based acceptor orbital with a more reduced $\mathrm{Cu}$ center in lieu of a high-valent $\mathrm{Cu}$ III oxidation state assignment. ${ }^{25}$ In the present instance, the presence of pre-edge features around $8979 \mathrm{eV} \pm 0.5 \mathrm{eV}$ traditionally assigned to a $\mathrm{Cu}^{\mathrm{II}}$ center mirrors the case of TEMPO ${ }^{*}$ coordinated to $\mathrm{Cu}^{\mathrm{II}}$ dihalides, in which again the acceptor orbital is dominated by ligand character. ${ }^{26}$ Moreover, pre-edge transitions at $\sim 8980.5 \mathrm{eV}$ have been observed in the $\mathrm{Cu}$ K-edge XAS spectrum of $\mathrm{Cu}^{\mathrm{I}}$ species with low lying ligand $\pi^{*}$ orbitals, such as in Cu-bipyridine species. ${ }^{27,28}$ In summary, these data demonstrate $\mathrm{Cu}$ K-edge XAS pre-edge peak energies are not altogether diagnostic of physical oxidation states in these often-covalent systems; nonetheless, they remain useful to discuss to test the veracity of electronic structure calculations.

In scrutinizing the $\mathrm{Cu}$ K-edge XAS spectra of all species, a single pre-edge feature is observed at $8978.7 \mathrm{eV}$ in the spectrum obtained for $\mathbf{1 1}$, the authentic cupric reference. This feature is assigned as a $\mathrm{Cu} 1 \mathrm{~s} \rightarrow 3 \mathrm{~d}$ transition consistent with the expected $\mathrm{Cu}^{\mathrm{II}}$ oxidation state assignment (Figure 5a). Similar pre-edge features are found in the $\mathrm{Cu}$ K-edge spectra of $\mathbf{5}$ and $\mathbf{6}$ at $8979.1 \mathrm{eV}$, although they appear at higher energy within the region conventionally ascribed to $\mathrm{Cu}^{\mathrm{II}}$. These features represent transitions into the LUMO of these complexes, which comprise an antibonding interaction between the $\mathrm{N} 2 \mathrm{p}_{X}$ of the imide and the weakly $\pi$-bonding $\mathrm{Cu}-\mathrm{Cu}$ MO formed by the in-phase combination of $\mathrm{Cu} 3 \mathrm{~d}_{\mathrm{x}}{ }^{2}-\mathrm{y}^{2}$. In contrast, the corresponding one-electron reduced anions $\mathbf{8}$ and $\mathbf{9}$ exhibit XANES spectra that are devoid of resolved pre-edge peaks (Figure 5b). These spectra have rising edges shifted to slightly lower energy, consistent with redox participation by $\mathrm{Cu}$. Higher energy rising edge 
transitions observed at ca. $8983 \mathrm{eV}$ gain intensity upon reduction from the neutral dicopper imido species. These intense rising edge features have been previously observed in $\mathrm{Cu} \mathrm{K}$ edge XAS spectra and are assigned primarily as $\mathrm{Cu} 1 \mathrm{~s} \rightarrow 4 \mathrm{p}$ transitions that can contain contributions from ligand-to-metal charge transfer (LMCT) shakedown transitions. ${ }^{29}$ Due to the dipole-allowed nature of an $\mathrm{s} \rightarrow \mathrm{p}(\Delta \mathrm{l}=+1)$ transition, larger intensities are observed compared to the relative weak, lower energy $\mathrm{Cu} 1 \mathrm{~s} \rightarrow 3 \mathrm{~d}$ and $\mathrm{Cu} 1 \mathrm{~s} \rightarrow \mathrm{L} \pi^{*}$ features. Moreover, the increase in the intensity of these $\mathrm{Cu} 1 \mathrm{~s} \rightarrow 4 \mathrm{p}$ rising-edge features is suggestive of greater $\mathrm{Cu}^{\mathrm{I}}$ character. These spectra are consistent with diminished $\mathrm{Cu}$ character in low-lying acceptor orbitals upon reduction of $\mathbf{5}$ and $\mathbf{6}$ to yield $\mathbf{8}$ and $\mathbf{9 ,}$ respectively.

$\mathrm{Cu} \mathrm{L}_{2,3}$-edges provide entry for a more quantitative analysis of the composition of frontier orbitals (Figure 5a,b). This analysis is possible because ligand orbital admixture into frontier $\mathrm{Cu} 3 \mathrm{~d}$-based orbitals modulates the allowedness and thus, intensity, of $\mathrm{Cu} 2 \mathrm{p} \rightarrow 3 \mathrm{~d}$ transitions. An inverse relationship between the ligand orbital admixture coefficient and the summed $\mathrm{L}_{3}\left(\mathrm{Cu} 2 \mathrm{p}_{3 / 2} \rightarrow \mathrm{Cu} 3 \mathrm{~d}\right)$ and $\mathrm{L}_{2}\left(\mathrm{Cu} 2 \mathrm{p}_{1 / 2} \rightarrow \mathrm{Cu} 3 \mathrm{~d}\right)$ intensities is observed. ${ }^{30}$ The $\mathrm{L}_{3}$ mainline features occur at $931.3 \mathrm{eV}(\mathbf{4})$ and $931.0 \mathrm{eV}(\mathbf{5})$ while the $\mathrm{L}_{3}$-edge of $\mathbf{1 1}$ occurs at $930.7 \mathrm{eV}$. Analysis of the summed $\mathrm{L}_{3}+\mathrm{L}_{2}$ integrated area reveals $20 \pm 1 \%$ and $24 \pm 1 \%$ $\mathrm{Cu} 3 \mathrm{~d}$ character (per $\mathrm{Cu}$ ) in the LUMO orbitals of 5 and $\mathbf{6}$, respectively (Figure $5 \mathrm{~d}$ ). These areas translate to $40 \% \mathrm{Cu} 3 \mathrm{~d}$ in the LUMO of 5 and $48 \% \mathrm{Cu} 3 \mathrm{~d}$ in the LUMO of $\mathbf{6}$. Accounting for the two indistinguishable copper centers, these experimental values accord well with those calculated for the total $\mathrm{Cu}$ character (vide infra) at $40.0 \%$ and $47.0 \%$ for 5 and 6 respectively, representing a covalent ground-state electronic structure in which significant mixing of ligand character is expected. The $\mathrm{Cu} \mathrm{L}_{2,3}$-edge spectra of the reduced species show evidence of significant photodamage, thus preventing a quantitative analysis of $\mathrm{Cu}$ character in the LUMO. Nonetheless, upon comparison of the first (and thus, leastdamaged) scans of $\mathbf{8}$ and $\mathbf{9}$ (Figure $5 \mathrm{~d}$ ), the $\mathrm{L}_{3}$ feature is significantly diminished in intensity as compared to $\mathbf{5}$ and $\mathbf{6}$, and a pronounced satellite feature around $934.8 \mathrm{eV}$ (iso-energetic with that observed in 10) is apparent. The weakness of the absorbance features for $\mathbf{8}$ and $\mathbf{9}$ implicates a ligand-dominated SOMO and suggests that both anionic $\mathbf{8}$ and $\mathbf{9}$ contain reduced copper centers relative to the unambiguous cupric sample $\mathbf{1 1 .}$

N K-edge XAS was obtained to assess the redox participation of the aryl nitrenoid moiety. Multiple features assigned as transitions from $\mathrm{N} 1 \mathrm{~s}$ to antibonding $M O s$ comprised of $\mathrm{N}$ and aryl character from the dipyrrin ligand are seen along the rising edge of the $\mathrm{N} \mathrm{K}$-edge for all species, consistent with our prior measurements of mononuclear dipyrrin-supported $\mathrm{Fe}$ imide/iminyl complexes ${ }^{31}$ as well as for analogous dipyrrin-supported nickel complexes ${ }^{32}$ (Figure 5f).

Additional, weak features at ca. 395-396 eV have been previously assigned as excitations into subvalent NAr-based MOs given the aforementioned Fe/Ni iminyl ${ }^{31,32}$ and copper nitrene ${ }^{9}$ precedent. These assignments are supported by electronic structure calculations (vide infra). In $\mathbf{5}$ and $\mathbf{6}$, these transitions are observed at $396.0 \mathrm{eV}$ and are assigned as transitions into a MO comprised of both $\mathrm{Cu} 3 \mathrm{~d}_{\mathrm{x}}{ }^{2}-\mathrm{y}^{2}$ and NAr $2 \mathrm{p}$ character. Upon oneelectron reduction, these transitions are shifted to lower energy at $395.2 \mathrm{eV}$, and the intensities are diminished. The diminished intensity of the $395.2 \mathrm{eV}$ features in $\mathbf{8}$ and $\mathbf{9}$ 
implicates an MO containing NAr $2 \mathrm{p}_{x}$ character participating in the $\mathbf{5 / 8}$ and $\mathbf{6 / 9}$ redox couples.

\subsection{Nitrenoid Reactivity.}

Transition metal bound imido complexes facilitate a range of nitrene transfer chemistry. ${ }^{33,34}$ Electron-rich metal imide complexes have been observed to undergo transfer to nucleophiles (e.g., tertiary phosphines, isocyanides, and $\mathrm{CO}$ ), whereas electrophilic imide complexes can exhibit olefin azirdination or the amination of $\mathrm{C}-\mathrm{H}$ bonds. ${ }^{35-40}$ To establish the effect of the dinuclear cuprous proximal arrangement afforded by the dimethylxanthene spacer, $\mathbf{1 0}$ was treated with substoichiometric aryl azides ( 0.5 equiv) at elevated temperatures $\left(60{ }^{\circ} \mathrm{C}, \mathrm{C}_{6} \mathrm{D}_{6}\right)$ to promote acetonitrile displacement, resulting in quantitative formation of azoarene and accompanied by formation of dimeric cuprous species $\left({ }^{t B u} \mathrm{~L}\right)_{2} \mathrm{Cu}_{2}(\mathbf{1 8})$ as the major coppercontaining species. Complex $\mathbf{1 8}$ displays substantial pyrrole torsion with respect to each pyrrole plane $\left(27.0(1)^{\circ}, 30.9(1)^{\circ}\right)$ to accommodate an exceptionally short intermetallic distance (2.443(2) ̊, Figure S-88). Complex 18 was similarly competent for azoarene formation from aryl azides at elevated temperatures. The absence of spectroscopically observable intermediates prior to azoarene formation corroborates the paramount functionality of the dimethylxanthene spacer in stabilizing $\left[\left({ }^{\mathrm{R}} \mathrm{dmx}\right) \mathrm{Cu}^{\mathrm{II}} 2\left(\mu^{2}-\mathrm{NAr}\right)\right]$ complexes against rapid azoarene formation.

The neutral $\left({ }^{\mathrm{R}} \mathrm{dmx}\right) \mathrm{Cu}_{2}\left(\mu^{2}-\mathrm{NAr}\right)$ complexes $(\mathbf{2}, \mathbf{3}, \mathbf{5}$, and $\mathbf{6})$ all undergo nitrene transfer upon exposure to nucleophiles. For example, treatment of the neutral complexes with excess tertiary phosphine $\left(\mathrm{PMe}_{3}, \mathbf{2}\right.$ or $\mathbf{3} ; \mathrm{PPh}_{3}, \mathbf{5}$ or $\left.\mathbf{6}\right)$ afforded the corresponding phosphinimide products with concomitant formation of the phosphine ligated $\left[\left({ }^{\mathrm{R}} \mathrm{dmx}\right) \mathrm{Cu}_{2} \mathrm{I}_{2}\left(\mathrm{PR}_{3}\right)_{2}\right]$ products, $\left({ }^{\mathrm{Mes}} \mathrm{dmx}\right) \mathrm{Cu}_{2}\left(\mathrm{PMe}_{3}\right)_{2}(\mathbf{1 2})$ and $\left({ }^{\mathrm{B} u} \mathrm{dmx}\right) \mathrm{Cu}_{2}\left(\mathrm{pPh}_{3}\right)_{2}$ (13), in good yields (Scheme 5). The phosphine-ligated products were verified by independent synthesis and characterized by single crystal X-ray diffraction (Figures S-83 and S-84). The electron-deficient imide complexes $\left({ }^{\mathrm{R}} \mathrm{dmx}\right) \mathrm{Cu}_{2}\left(\mu^{2}-\mathrm{N}\left(3,5-\left(\mathrm{F}_{3} \mathrm{C}\right)_{2} \mathrm{C}_{6} \mathrm{H}_{3}\right)\right)(\mathbf{3}, \mathbf{6})$ reacted rapidly with excess tert-butyl isocyanide $\left(\mathrm{CN}^{t} \mathrm{Bu}\right)$ to afford the corresponding carbodiimide product. In contrast, the reaction of electron-rich imidos $\left({ }^{\mathrm{R}} \mathrm{dmx}\right) \mathrm{Cu}_{2}\left(\mu^{2}-\mathrm{N}\left(\mathrm{C}_{6} \mathrm{H}_{4} \mathrm{OMe}\right)\right)(\mathbf{2}, \mathbf{5})$ with $\mathrm{CN}^{t} \mathrm{Bu}$ yielded the resulting azoarene product (Scheme 6). The copper-containing species from these reactions was identified as $\left({ }^{\mathrm{R}} \mathrm{dmx}\right) \mathrm{Cu}_{2}\left(\mathrm{CN}^{t} \mathrm{Bu}\right)_{2}\left(\mathrm{R}\right.$ : Mes, $\left.14 ;{ }^{\mathrm{Bu}}, 15\right)$ and confirmed by independent synthesis and single crystal $\mathrm{X}$-ray diffraction. The difference in reactivity profiles can be attributed to varying radical-localization at the nitrogen bridgehead (vide infra).

While imido complexes $2, \mathbf{3 , 5}$, and $\mathbf{6}$ were thermally stable $\left(120^{\circ} \mathrm{C}, 24 \mathrm{~h}\right)$, azoarene generation from the imido complexes was promoted by treatment of the imide complexes with pyridine, 4-(dimethylamino)pyridine (DMAP), or cyclohexene. For example, $\mathbf{2}$ decays as a first-order process in the presence of excess DMAP (9 equiv) with heating $\left(65^{\circ} \mathrm{C}, 10 \mathrm{~h}\right)$ to afford ( $\left.{ }^{\mathrm{Mes}} \mathrm{dmx}\right) \mathrm{Cu}_{2}(\mathrm{dmap})_{2}(\mathbf{1 6})$ and the corresponding azoarene in excellent yield (87\%) by both ${ }^{19} \mathrm{~F}$ and ${ }^{1} \mathrm{H}$ NMR with no spectroscopically observable intermediates. In the presence of weak $\mathrm{H}$ atom donors such as diphenylhydrazine, treatment of $\mathbf{2}$ or $\mathbf{3}$ with DMAP affords the corresponding aniline as well as $\mathbf{1 6}$ under more mild conditions $\left(35^{\circ} \mathrm{C}, 6 \mathrm{~h}\right)$. 
None of the $\left({ }^{\mathrm{R}} \mathrm{dmx}\right) \mathrm{Cu}_{2}\left(\mu^{2}-\mathrm{NAr}\right)$ complexes $(\mathbf{2}, \mathbf{3}, \mathbf{5}$, and $\mathbf{6})$ exhibited propensity toward $\mathrm{H}$-atom abstraction at room temperature, even upon exposure to weak $\mathrm{H}$-atom sources (e.g., 2-hydroxy-2-azaadamantane; $\mathrm{BDE}_{\mathrm{O}-\mathrm{H}}=69 \mathrm{kcal} \mathrm{mol}^{-1}$ ). However, the anion 7 was observed to intramolecularly aminate at room temperature. Allowing solutions of $\mathbf{7}$ to stand at room temperature over several minutes generated several new diamagnetic species by ${ }^{1} \mathrm{H}$ NMR, with one species identified as a di(cuprous) product in which intramolecular amination of the proximal mesityl C-H bond has occurred (17, Scheme 7). Single crystals of the reaction product 17 were grown by vapor diffusion of diethyl ether into a concentrated solution of $\mathbf{1 7}$ in tetrahydrofuran. The molecular structure obtained by crystallography, while poor, was sufficient to establish the connectivity (Figure S-41). This reaction proceeds through formal loss of a single $\mathrm{H}$ atom, which may contribute to the presence of multiple unidentified species in crude ${ }^{1} \mathrm{H}$ NMR spectrum. Attempts to mitigate ligand functionalization by introduction of external weak $\mathrm{C}-\mathrm{H}$ or $\mathrm{O}-\mathrm{H}$ bonds to 7 were unsuccessful.

In contrast to the reactivity exhibited by the $\left({ }^{R} \mathrm{dmx}\right) \mathrm{Cu}_{2}\left(\mu^{2}-\mathrm{NAr}\right)$ complexes $(\mathbf{2}, \mathbf{3}, \mathbf{5}$, and $\mathbf{6})$ complexes and the anion $\mathbf{7}$, the more thermally robust imido anions $\left[\left({ }^{t B u} \mathrm{~L}\right) \mathrm{Cu}_{2}(\mu 2-\mathrm{NAr})\right]^{-} \mathbf{8}$ and 9 were unreactive toward triphenylphosphine or weak $\mathrm{C}-\mathrm{H}$ bonds and $\mathrm{H}-$ atom donors. Though containing comparable \% N 2p covalency values (5/8: $15 \% / 22 \%$ vs. 6/9: $17 / 25 \%$ ), formation of the corresponding iminyl upon reduction ultimately results in most of the spin density of the frontier RAMO being delocalized over the aryl ring of the NAr substituent.

\section{DISCUSSION}

\subsection{Synthesis and Structure.}

The pacman bis(dipyrrin) dicopper complexes are well suited to undergo nitrene capture from aryl azides. While the dicuprous precursors do not exhibit substantial intercopper interactions (e.g., 13, $\mathrm{d}_{\mathrm{Cu}-\mathrm{Cu}}:>6.20 \AA$ ), the two-electron oxidized imido complexes have shorter interactions $\left(d_{\mathrm{Cu}-\mathrm{Cu}}: 2.82-2.87 \AA\right)$ enforced by the bridging imido motif. The $\mathrm{Cu}-\mathrm{Cu}$ separation is shortened compared to the bridging aryl imido complexes reported by Warren (2.911(1) $\AA)^{5}$ but longer than the isoelectronic dicopper carbene complexes (2.464(1) $\AA$ ). ${ }^{41}$ The $\mathrm{Cu}-\mathrm{N}_{\text {imide }}$ distances are consistent with reported $\mu^{2}$-imido (1.794(5) to 1.808(5) $\AA)^{5-8}$ and $\mu^{3}$-copper imidos (1.842(5) to $\left.1.893(6) \AA\right) .{ }^{42,43}$ Upon reduction, each of the crystallographically characterized complexes 7-9 exhibit expansion of the $\left[\mathrm{Cu}_{2} \mathrm{~N}\right]^{1+}$ core, consistent with increased electron richness. The near-identical coordination environment about each copper ion in 7-9 contrasts the apparent valence-localized oxo-bridged $\mathrm{Fe}^{\mathrm{II}} \mathrm{Fe}^{\mathrm{III}}$ complex previously isolated within this framework. ${ }^{13}$ Each of the reduced nitrenoid complexes also features a contracted $\mathrm{N}_{\text {imido }}-\mathrm{C}_{\text {ipso }}$ bond $(\mathbf{7}, 1.318(4) \AA ; 8,1.351(3) \AA$; and 9, 1.342(3) $\AA$ ) which approximate as $\mathrm{C}-\mathrm{N}$ double bonds akin to those found in pyridine (Table 1). Thus, the nitrenoid units take on more of a ketamide resonance form similar to those previously reported for the bimolecularly coupled $\left[\left({ }^{\mathrm{EMlnd}} \mathrm{L}\right)-\mathrm{Cu}\right]_{2}(\mathrm{~N}(3,5-$ $\left.\left.(\mathrm{MeO})_{2} \mathrm{C}_{6} \mathrm{H}_{3}\right)_{2}\right)_{2}\left(\mathrm{~N}_{\text {imido }}-\mathrm{C}_{\text {ipso }}\right.$ bond lengths: 1.257(5) and 1.276(6) $\AA$ ). ${ }^{9}$ Furthermore, redox noninnocence behavior of the aryl fragment is apparent upon inspection with elongation of the $\mathrm{C}_{\mathrm{ipso}}-\mathrm{C}_{\text {ortho }}$ bond upon reduction. Such arene distortions have been 
observed in previously isolated dipyrrin-supported quintet iron iminyl complexes, ${ }^{31,44,45}$ doublet nickel iminyl complexes,${ }^{32}$ and triplet copper nitrene complexes, ${ }^{9}$ suggesting a delocalized ${ }^{2}[\mathrm{NAr}]$ vacancy is potentially engendered upon one-electron reduction. Such a transformation is unusual, as the reductions of the neutral imido complexes proceed with oxidation of the most electronegative atom of the $\left[\mathrm{Cu}_{2}\left(\mu^{2}-\mathrm{NAr}\right)\right]$ core.

\subsection{Calculated X-ray Absorption Spectra.}

Electronic structure calculations were carried out to facilitate discussion of the XAS data and to interrogate the nature of the redox event linking the neutral and anionic dicopper nitrenoid complexes. The electronic structures that emerge, at least for the neutral species 5 and 6, are not altogether straightforward. Considering each dipyrrin-Cu center in isolation, the highest $\mathrm{Cu} 3 \mathrm{~d}$-based orbital in each $\mathrm{Cu}$-dipyrrin fragment is predicted to be $3 \mathrm{~d}_{\mathrm{x}}{ }^{2}-\mathrm{y}^{2}$ (Figure 6). This affords a basis for two linear combinations representing weakly interacting $\mathrm{Cu}_{2} \pi$ and $\pi^{*}$ orbitals. Introduction of the NAr $2 \mathrm{p}_{x}$ perpendicular to the Ar plane produces a 3-center MO framework representative of a 3-center-4-electron bond. This simple picture predicts that the redox-active molecular orbital (RAMO) is best described as $\psi^{*} \approx\left(\mathrm{Cu}_{2} \pi-\right.$ NAr $2 p_{X}$ ), an overall $\pi^{*} \mathrm{MO}$, in complete accord with observations from XAS. The $\mathrm{Cu}$ orbitals are depressed compared to those of the nitrenoid motif, resulting in an inverted ligand field with NAr $2 \mathrm{p}_{\mathrm{x}}$ character dominant in the RAMO. We note that this is an idealized picture that assumes $\mathrm{C}_{2 V}$ symmetry and neglects $\mathrm{Cu}-\mathrm{Cu}$ interactions, and in fact the two $\mathrm{LCu}$ inner coordination spheres do not perfectly overlay as would be required for this picture to be exactly operative; each complex exhibits significantly nonzero dihedral angles defined by the two $\mathrm{Cu}$ and two dipyrrin meso-C atoms. This deviation from ideal symmetry becomes apparent in scrutinizing orbitals derived from electronic structure calculations (vide infra).

Scalar relativistic single-point DFT calculations employing the B3LYP hybrid density function with the $\mathrm{CP}(\mathrm{PPP})$ basis set on $\mathrm{Cu}$ and the scalar-relativistically recontracted ZORAdef2-TZVP(-f) basis set on all other atoms were carried out on all compounds for which XAS data were obtained. For neutral $\mathbf{5}$ and $\mathbf{6}$, broken symmetry (BS) singlet diradical (BS $1,1)$ solutions were found to have lower energy relative to corresponding conventional unrestricted Kohn-Sham (UKS) solutions. For $\mathbf{8}$ and 9, no BS solutions were obtained. Rather, standard doublet $(S=1 / 2)$ solutions emerged.

The aforementioned single point DFT solutions were used as starting points for timedependent DFT (TDDFT) calculations of $\mathrm{Cu}$ and $\mathrm{N}$ K-edge XAS. TDDFT calculations are now well-established as a means to produce simulated XAS pre-edge data with high fidelity to experiment after proper calibration ${ }^{27,46-48}$ The present compounds do not present an exception to this trend, however the underlying electronic structure interpretation requires extended explanation.

Upon application of a linear energy correction produced via correlation of TDDFTcalculated with experimental pre-edge peak energies for all compounds under discussion, the $\mathrm{Cu} \mathrm{K}$ pre-edge and rising edge peak energies accord well with experiment (Figures S-62 and $\mathrm{S}-63)$. These calculations were then used to assign acceptor MOs underlying given transitions. For 10, the observed $8982.4 \mathrm{eV}$ transition is predicted at $8982.1 \mathrm{eV}$ as a $\mathrm{Cu} 1 \mathrm{~s}$ 
$\rightarrow 4 \mathrm{p}$ excitation, where the acceptor MO exhibits some acetonitrile $\mathrm{C}-\mathrm{N} \pi^{*}$ character. These calculations predict a weak $\mathrm{Cu} 1 \mathrm{~s} \rightarrow$ LUMO feature at $8980.6 \mathrm{eV}$ (dipyrrin $\pi^{*}$ orbital) that is not resolved experimentally. The calculated spectrum of $\mathbf{1 1}$ reproduces the $8987.7 \mathrm{eV} \mathrm{Cu} 1 \mathrm{~s} \rightarrow 3 \mathrm{~d}$ feature while also predicting an unresolved $\mathrm{Cu} 1 \mathrm{~s} \rightarrow \mathrm{L} \pi^{*}$ transition at $8983.4 \mathrm{eV}$. The $8979.0 \mathrm{eV} \mathrm{Cu} 1 \mathrm{~s} \rightarrow \mathrm{RAMO}$ transitions are reproduced for $\mathbf{5 / 6}$, and upon inspection of the calculated spectra for $\mathbf{8 / 9}$ weak $\mathrm{Cu} 1 \mathrm{~s} \rightarrow$ RAMO transitions are observed at slightly higher energy relative to their neutral counterparts $(8979.5$ and $8979.9 \mathrm{eV}$ respectively). In addition, 8 and $\mathbf{9}$ display weak pre-edge features at $8981.1 \mathrm{eV}$ corresponding to $\mathrm{Cu} 1 \mathrm{~s} \rightarrow \mathrm{L} \pi^{*}$ transitions, shifted to lower energy compared to the 8982.9 $\mathrm{eV}$ features predicted features for the neutral complexes. The diminished intensity of the $\mathrm{Cu}$ $1 \mathrm{~s} \rightarrow 3 \mathrm{~d}$ transitions and observed energy shifts supported the contention that 8 and $\mathbf{9}$ possess RAMOs with diminishing copper character and N-localized spin. Fewer acceptor holes are available in NAr, and participation of NAr in the redox is supported by the energetic red shift, indicating a more electron-rich NAr fragment.

Agreement between experiment and theory is maintained upon returning to the $\mathrm{N}$ K-edge XAS spectra (Figure S-64 and S-65). Examining the spectrum of 10, the $398.0 \mathrm{eV}$ feature in the experimental N K-edge is predicted at $397.4 \mathrm{eV}$ as a transition into the dipyrrin-based LUMO, while the $398.9 \mathrm{eV}$ feature is predicted as a combination of transitions into higher energy MOs of $\mathrm{Cu} 4 \mathrm{p}$ and acetonitrile $\pi^{*}$ parentage. For 11, the observed 397.2 and 398.0 $\mathrm{eV}$ lower-energy shoulders that represent transitions into the predominantly $\mathrm{Cu} 3 \mathrm{~d}$ SOMO, containing mixing with $\mathrm{Cl} 3 \mathrm{p}$ and dipyrrin $\mathrm{N} 2 \mathrm{p}$, and lower-lying dipyrrin $\pi^{*}$ orbitals, are predicted at 396.3 and $397.8 \mathrm{eV}$. Lastly, examining the N K-edge XAS spectra of the di(copper) species, the $396.0 \mathrm{eV}$ feature of $\mathbf{5}$ is predicted at $396.3 \mathrm{eV}$ as a transition into the RAMO containing $47 \% \mathrm{Cu}$ and $30 \% \mathrm{NAr}(15 \% \mathrm{~N} 2 \mathrm{p})$. The lower energy $395.2 \mathrm{eV}$ feature of $\mathbf{8}$ is once again reproduced, predicted at $395.6 \mathrm{eV}$ as a transition into the RAMO that contains 34\% Cu and 44\% NAr (17\% N 2p). Similar results were obtained for $\mathbf{6 / 9}$ (Figures S-64 and S-65).

Unfortunately, quantification ${ }^{48}$ of $\mathrm{N} 2 \mathrm{p}$ covalency from the given spectra was unreliable due to photodamage and hence rapid reduction in the intensity of the 396.0 and $395.2 \mathrm{eV}$ features that is seen upon carrying out multiple scans at the same sample location. However, returning to the $\mathrm{Cu} \mathrm{L}_{2,3}$-edge data, the ca. $40 \%$ and $47 \%$ overall $\mathrm{Cu} 3 \mathrm{~d}$ participation in the LUMOs of 5 and 6, respectively, accord with the $40 \% \mathrm{Cu} 3 \mathrm{~d}$ and $47 \% \mathrm{Cu} 3 \mathrm{~d}$ predicted by DFT. Together with anisotropic ${ }^{14} \mathrm{~N}$ hyperfine coupling manifesting in the frozen-solution EPR data obtained for $\mathbf{6}$ and $\mathbf{9}$ as well as the well-resolved NAr features in the corresponding $\mathrm{N}$ K-edge XAS spectra, these support the contention that there is a high degree of NAr 2 p character in the RAMO of the $\mathbf{5 / 8}$ and $\mathbf{6 / 9}$ couples.

\subsection{Ab Initio Calculations.}

While the TDDFT calculations of the XAS data exhibit high fidelity to experiment, a paradoxical picture emerges when more deeply probing the electronic structure of neutral complexes $\mathbf{5}$ and $\mathbf{6}$, for which BS $(1,1)$ solutions are encountered via DFT. Examination of the acceptor MOs used to generate the TDDFT-calculated spectra following a quasirestricted orbital (QRO) transformation reveals that they are $\left[\mathrm{Cu}_{2} \pi\right.$-NAr $\left.2 \mathrm{p}\right] \pi^{*}$, as 
predicted qualitatively (Figure S-69). However, these are the canonical orbitals generated during the BS calculation. Inspection of the unrestricted corresponding orbitals (UCOs), which reflect the magnetic orbitals of the singlet diradical and are mandatory for TDDFT analysis ${ }^{49}$ presents a problem (Figure S-69). These occupied spin orbitals are predicted to have diminished overlap ( $S=0.74$ and $S=0.56$ for 5 and $\mathbf{6}$, respectively) and overall are antiferromagnetically coupled with $J$ values of -2631 and $-1802 \mathrm{~cm}^{-1}$ for $\mathbf{5}$ and $\mathbf{6}$, respectively, in accord with the experimentally established diamagnetic natures of these complexes. However, these occupied UCOs are effectively of the same nature as the unoccupied canonical MOs involved in the XAS pre-edge excitations.

This paradox plausibly arises due to the multiconfigurational nature of the ground state electronic structures of $\mathbf{5}$ and $\mathbf{6}$. Ab initio, complete active space self-consistent field (CASSCF) calculations were carried out on these complexes using CAS $(10,9)$ active spaces. ${ }^{50}$ These active spaces were chosen to balance flexibility with computational expense. Truncated structural models $\mathbf{5}^{\prime}$ and $\mathbf{6}^{\prime}$ were generated by removing tBu substituents from the pyrrole rings and optimizing $\mathrm{H}$ atom positions for similar reasons of economy. Hybrid DFTcalculated orbitals were used as starting points for the CASSCF calculations, with orbitals included in the active space comprising those involved in the $\mathrm{Cu}_{2}-\mathrm{NAr} \pi$ interaction as well as some dipyrrin MOs. These calculations were carried out using the ZORA-def2TZVP(-f) basis on $\mathrm{Cu}$ and N, with ZORA-def2-SVP on all other atoms. For all cases, state averaging was used to facilitate convergence, with five singlet and five triplet roots calculated. The strongly contracted N-electron valence perturbation theory 2 (NEVPT2) correction was applied to the CASSCF state energies to account for dynamical electron correlation. The calculated singlet-triplet gaps after NEVPT2 correction are 1341.3 and $808.6 \mathrm{~cm}^{-1}$ for $\mathbf{5}^{\prime}$ and $\mathbf{6}^{\prime}$ in line with experimental magnetic behavior. A molecular orbital diagram reflecting the leading ground state configurations for $\mathbf{6}^{\prime}$ resulting from the CASSCF calculation is given in Figure 7. The analogous diagram for $\mathbf{5}^{\prime}$ is qualitatively similar and is included in the Supporting Information (Figure S-68a). The ground state singlet comprises two leading configurations with weights of ca. $50 \%$ and $40 \%$. These configurations reflect either double occupation of the $\mathrm{Cu}_{2} \pi^{*} \mathrm{MO}$ or the $\left(\mathrm{Cu}_{2} \pi\right.$-NAr $\left.2 \mathrm{p}_{x}\right) \pi^{*} \mathrm{RAMO}$, respectively. These configurations can be effectively be averaged to yield the BS picture.

A qualitative frontier MO diagram for 9 is given in Figure $7 \mathrm{~b}$ for comparison to $\mathbf{6}$. The diagram for $\mathbf{8}$ is similar and is included as Figure S-68b. These single-configurational doublet states possess an unpaired electron in the $\left(\mathrm{Cu}_{2} \pi\right.$-NAr $\left.2 \mathrm{p}_{x}\right) \pi^{*}$ RAMO in accord with predictions and the observed decreased intensities of the $\mathrm{N} \mathrm{K}$ pre-edge peaks upon in the monoanions relative to the neutral analogues.

\subsection{Electronic Structure of the Bridged Imidos.}

All of the dicopper imido complexes $(\mathbf{2}, \mathbf{3}, \mathbf{5}$, and $\mathbf{6})$ feature highly multiconfigurational singlet ground states (Figure 7). The singlet configurations emerging from these calculations are consistent with the diamagnetic electronic configurations observed at room temperature as assessed by multinuclear NMR and a lack of any discernible EPR signal. Via CASSCF analysis, we assess the most consistent electronic description for all these complexes comprise singlet ground states whose two major configurations are defined by (a) double 
population of $(\mathrm{Cu}-\mathrm{Cu}) \pi^{*}$ with no contribution from the imido unit (48\%) and (b) double population of a $\left[\left(\mathrm{Cu}_{2} \pi\right.\right.$-NAr) $] \pi^{*}$ interaction contributing $40 \%$. Configuration 1 illustrates how the cupric character in the dicopper imidos is diminished, consistent with the XAS data (Figure 7a).

The formally mixed valence anionic imidos (7-9) possess doublet ground states exhibiting well-defined EPR signals between 4-295 K (Figures S-21, S-22, S-24, and S-25). Solutionphase EPR spectra display isotropic hyperfine coupling (i.e., electronic contribution from the $2 \mathrm{~s}$ orbital), dominated by $\mathrm{Cu}$ character with minimal $\mathrm{N}$ contribution and consistent with spectra observed for fully delocalized, Class IIIA mixed valence dicopper complexes ${ }^{51-53}$ in the Robin-Day classification. ${ }^{54}$ This observation is rationalized by considering the nitrogen contribution to the RAMO arises from the $2 p_{X}$ component, leading to an anisotropic component only apparent at lower temperatures. ${ }^{55}$ In the frozen solution EPR spectrum, a high degree of unpaired electron localization to $\mathrm{N} 2 \mathrm{p}_{X}$ is apparent, contributing to the hyperfine coupling alongside the copper centers. The temperature-dependence of the EPR spectra are superficially inconsistent with a Class IIIA mixed valence assignment and more reminiscent of Class II species ${ }^{56-59}$ but are accounted for when considering that the temperature dependence arises not from changes in electronic structure but from the participation of anisotropic hyperfine contributions. ${ }^{55}$ While complexes 7-9 do feature optical transitions in the near IR region (Figure S-59), their corresponding neutral precursors also feature prominent transitions at similar energies. Indeed, both $\left({ }^{t B u} \mathrm{dmx}\right) \mathrm{Cu}_{2}\left(\mu^{2}-\right.$ $\left.\mathrm{N}\left(\mathrm{C}_{6} \mathrm{H}_{4} \mathrm{OMe}\right)\right)(5)$ and its anionic analogue 8 feature absorptions at the same energy $(\sim 1300$ $\mathrm{nm})$ with near equal intensity $\left(\varepsilon \approx 500 \mathrm{M}^{-1} \mathrm{~cm}^{-1}\right)$, whereas the NIR band for $\left[\left({ }^{\left({ }^{B u} \mathrm{dmx}\right.}\right) \mathrm{Cu}_{2}\left(\mu^{2}-\mathrm{N}\left(3,5-\left(\mathrm{F}_{3} \mathrm{C}\right)_{2} \mathrm{C}_{6} \mathrm{H}_{3}\right)\right)\right]^{-}(\mathbf{9})$ does shift to lower energy $(1750 \mathrm{~nm})$ than its neutral precursor $(6,1450 \mathrm{~nm})$.

Thus, the origins of the NIR absorption bands cannot exclusively arise from IVCT between the two $\mathrm{Cu}$ centers. Using calculated $J$ parameters of $-2631(5)$ and $-1802 \mathrm{~cm}^{-1}(\mathbf{6})$ yields $2 \mathrm{H}_{\mathrm{AB}}$ values ${ }^{60,61}$ in the visible region between $\sim 580$ and $\sim 700 \mathrm{~nm}$, in accord with observed IVCTs for the mixed valence $\mathrm{Cu}_{\mathrm{A}}$ species. ${ }^{62}$ We note the IVCT transition may be obscured by the intense dipyrrin Soret band transition. Nonetheless, TDDFT analysis of the NIR absorptions indicates the transitions are representative of metal-to-ligand charge transfer (MLCT) and not intervalence charge transfer (Figures S-71 and S-72). Inspection of individual transitions within this region (300-1200 nm, Table S-1) calculated via TDDFT did not reveal any excitations that could clearly be ascribed to IVCT transitions. Thus, the highly covalent, three-centered bonding interaction of the $\left[\mathrm{Cu}_{2}(\mathrm{NAr})\right]$ core leads to full electronic delocalization reserved for mixed valence complexes in the Class IIIA regime.

The clearest picture of the electronic structure for the anionic imidos arises from the combined $\mathrm{Cu}\left(\mathrm{L}_{2,3}, \mathrm{~K}\right.$-edges) and $\mathrm{N}$ (K-edge) XAS spectra. While neutral imidos 5 and $\mathbf{6}$ feature prominent pre-edge absorptions in the $\mathrm{Cu} \mathrm{K}$-edge spectra, the anionic imidos $(\mathbf{8}, \mathbf{9})$ lack clear experimental pre-edge features (Figure 5b, inset) similar to cuprous standard $\left.{ }^{\left({ }^{B}{ }^{2}\right.} \mathrm{L}\right) \mathrm{Cu}^{\mathrm{I}}(\mathrm{NCMe})(\mathbf{1 0})$. The weak pre-edge features observed in TDDFT calculations can be attributed to addition of an electron to the $\mathrm{Cu}$ and $\mathrm{N}$ based LUMO in $\mathbf{5 / 6}$. Both neutral $\mathbf{5}$ and 6 exhibit intense $\mathrm{L}_{3}$ main line features at energies $(\sim 930 \mathrm{eV})$ consistent with mononuclear analogues $\left(\left({ }^{\mathrm{Bu}} \mathrm{L}\right) \mathrm{Cu}{ }^{\mathrm{II}} \mathrm{Cl}, \mathbf{1 1}\right)$, while the $\mathrm{L}_{3}$ feature is significantly diminished in the reduced 
nitrenoids with prominent satellites at higher energy (935 eV) (Figure 5c,d) akin to the mononuclear cuprous analogue $\left({ }^{(B u} \mathrm{L}\right) \mathrm{Cu}(\mathrm{NCMe})(\mathbf{1 0})$. Lastly, the $\mathrm{N}$ K-edge reveals a systematic shift of the pre-edge absorptions as the singly occupied molecular orbital becomes more localized on the (NAr) fragment, suggesting increased iminyl radical character exists for the anions $\mathbf{8}$ and $\mathbf{9}$. In addition, the decreased intensity of the N K-edge pre-edge feature is indicative of population of the $\mathrm{N}$ based LUMO in $\mathbf{5 / 6}$ by reduction, resulting in a SOMO with significant $\mathrm{N}$ character.

The foregoing data indicate the reduced $\left[\mathrm{Cu}_{2}\left(\mu^{2}-\mathrm{NAr}\right)\right]^{-}$complexes largely exhibit iminyl character. The copper centers in the anionic imido complexes exhibit diminished $\mathrm{Cu}$ character in acceptor orbitals based on the $\mathrm{Cu} \mathrm{L}_{2,3}$-edge data and Lowdin spin density analysis. These data together are typical of bridged $\mathrm{Cu}$ complexes exhibiting highly covalent cores with substantial ligand participation in the electroactive orbitals. ${ }^{63-67}$ The RAMO of 8 and 9 display comparable $\mathrm{Cu}$ character to other mixed valence $\mathrm{Cu}$ species such as $\mathrm{Cu}_{\mathrm{A}}(44 \%$ $\mathrm{Cu}),{ }^{67}\left[\left(\mathrm{~L}^{\mathrm{iPrdacoS}} \mathrm{Cu}\right)_{2}\right]^{+}(38 \% \mathrm{Cu}),{ }^{67}$ and $\left[\left\{\left({ }^{\left(\mathrm{Bu}_{2} \mathrm{PNP}\right) \mathrm{Cu}}\right\}_{2}\right]^{+}(24 \% \mathrm{Cu}) .{ }^{63}\right.$ Nonetheless, we note $\mathbf{8}$ and $\mathbf{9}$ are lower coordinate (tri-coordinate instead of tetra-coordinate) and contain strictly hard nitrogen atom in the primary coordination sphere in lieu of polarizable sulfur and phosphorus. Indeed, the $\mathrm{N} \mathrm{K}$-edge data reveal common features between the reduced imidos 8 and 9 with other $\mathrm{N}$-centered, radical species. ${ }^{9,31,32}$ Whereas the previously reported metal-supported iminyl structures exhibit bond-length distortions within the iminyl fragment consistent with hole delocalization, complexes $\mathbf{8}$ and $\mathbf{9}$ do not exhibit substantial distortions aside from enhanced $\mathrm{N}-\mathrm{C}_{\mathrm{ipso}} \pi$-bonding upon NAr reduction. The electronic description is corroborated with the calculated electronic structure which reveals a highly (NAr)-centered RAMO (Figure 7b). Insight into the increasing cuprous character can be gleaned from comparing the frontier orbitals of $\mathbf{6}$ and $\mathbf{9}$. While chemical reduction of $\mathbf{6}$ occurs by population of the LUMO. the ground state of imido $\mathbf{6}$ is multiconfigurational with nearly equal contributions from $(\mathrm{Cu}-\mathrm{Cu}) \pi^{*}(213)$ and $\left[\left(\mathrm{Cu}_{2} \pi\right.\right.$-NAr) $] \pi^{*}$ (214) singlet configurations. The frontier orbital configuration of 9 leads to double population of $(\mathrm{Cu}-\mathrm{Cu}) \pi^{*}$ (which was only partially occupied in $\mathbf{6}$ ), and partial population of $\left[\left(\mathrm{Cu}_{2} \pi\right.\right.$ $\mathrm{NAr}$ ) $\pi^{*}$ (Figure $7 \mathrm{~b}$ ), effectively reducing the overall $\mathrm{Cu}_{2}-\mathrm{N}$ bond order by 1.5 . Thus, the bridging ligand radical character was quite remarkably achieved through reduction, not oxidation, of the $\left[\mathrm{Cu}_{2}\left(\mu^{2}-\mathrm{NAr}\right)\right]$ core.

\subsection{Reactivity of the Imido Complexes.}

The neutral imidos $(\mathbf{2}, \mathbf{3}, \mathbf{5}$, and $\mathbf{6})$ exhibit reaction chemistry reminiscent of the electrophilic imido complexes. The nitrene motif can be transferred to incoming nucleophiles (e.g., tertiary phosphines and alkyl isocyanides), but the aryl-substituent on the imide influences the reaction trajectory. The more electrophilic $\left[\mathrm{Cu}_{2}\left(\mu^{2}-\mathrm{N}\left(3,5-\left(\mathrm{F}_{3} \mathrm{C}\right)_{2} \mathrm{C}_{6} \mathrm{H}_{3}\right)\right)\right]$ imido complexes 3 and $\mathbf{6}$ undergo clean nitrene transfer to nucleophilic reagents $\left(\mathrm{PR}_{3}, \mathrm{CN}^{t} \mathrm{Bu}\right)$, while the $\left[\mathrm{Cu}_{2}\left(\mu^{2}-\mathrm{N}\left(\mathrm{C}_{6} \mathrm{H}_{3} \mathrm{OMe}\right)\right)\right]$ imido complexes $\mathbf{2}$ and $\mathbf{5}$ produce azoarene from nitrene coupling upon reaction with ${ }^{\mathrm{BuNC}}$. Several simple ligands (e.g., pyridine and DMAP) also can induce azoarene formation at elevated temperatures, which do not require direct attack of substrate on the imido fragment. Indeed, each of the nitrene transfer reactions observed can occur from substrate attack on $\left[\mathrm{Cu}_{2}\left(\mu^{2}-\mathrm{NAr}\right)\right]$ core, potentially activating the core via ligation (e.g., $\left[\mathrm{Cu}_{2}\left(\mu^{2}-\mathrm{NAr}\right)(\mathrm{L})\right], \mathrm{L}=$ substrate) or inducing $\mathrm{Cu}-\mathrm{N}$ cleavage to form a 
transient terminal imido complex. The activated dicopper core can then undergo rapid bimolecular coupling or undergo free nitrene expulsion. However, the complete selectivity of nitrene coupling to yield azoarene argues against free nitrene expulsion without the detection of free nitrene products (e.g., aziridine, $\mathrm{C}-\mathrm{H}$ amination, and nitrene aryl-ring expansion). The observed difference in reactivity between electron rich and electron poor imido complexes may arise from the relative stabilities of the triplet and singlet nitrene states on the transient $[\mathrm{Cu}(\mathrm{L}) \mathrm{Cu}(\mathrm{NAr})]\left(\mathrm{L}=\mathrm{PR}_{3}, \mathrm{CN}^{t} \mathrm{Bu}\right)$ formed. The Cu-bound ${ }^{3}\left[\mathrm{~N}\left(\mathrm{C}_{6} \mathrm{H}_{4} \mathrm{OMe}\right)\right]$ would favor reacting with triplet configuration as opposed to added singlet reactants. The absence of intramolecular benzylic amination, intermolecular $\mathrm{H}$ atom abstraction, or ring expansion of the nitrene aryl ring argue against dissociation of free nitrene in solution. Nonetheless, the release of singlet nitrene cannot be fully discounted, noting that, whereas ${ }^{1}\left[\mathrm{~N}\left(3,5-\left(\mathrm{F}_{3} \mathrm{C}\right)_{2} \mathrm{C}_{6} \mathrm{H}_{3}\right)\right]$ may have an appreciable singlet lifetime in solution, intersystem crossing from ${ }^{1}\left[\mathrm{~N}\left(4-\mathrm{MeOC}_{6} \mathrm{H}_{3}\right)\right]$ to a triplet ground state is exceptionally fast, ${ }^{68}$ perhaps explaining the discrepancies in reactivity upon $\mathrm{CN}^{t} \mathrm{Bu}$ treatment.

Aside from the intramolecular amination exhibited by thermally unstable 7, the reduced imido complexes show no propensity for nitrene transfer to substrate or proclivity toward $\mathrm{H}$ atom abstraction chemistry. These results suggest the presence of radical character at the nitrogen bridgehead of the imide motif enables amination of proximal ligand, benzylic $\mathrm{C}-\mathrm{H}$ bonds at room temperature. Despite the presence of bona fide radical character at the bridgehead, 7 fails to perform intermolecular amination chemistry. This observation may be attributed to the relatively reducing potential of 7 , rendering the resulting $\mathrm{N}-\mathrm{H}$ bond excessively weak. Moreover, the inability of the ligand to support a zerovalent copper center renders two-electron reduction chemistry from $\mathbf{7}$ unlikely. The dipyrrin ligand substituents (Mes in 7, ${ }^{\mathrm{B}} \mathrm{Bu}$ in $\mathbf{8}$ and 9) may sterically shield the iminyl fragment from incoming substrate, especially given the SOMO character is localized on the $\mathrm{Np}_{X}$ orbital normal to the $\left[\mathrm{Cu}_{2}\left(\mu^{2}-\mathrm{NAr}\right)\right]$ plane. Thus, the amination exhibited by 7 may result from the optimally oriented, mesityl benzylic methyl substituents, while the $\mathrm{C}-\mathrm{H}$ bonds of the ${ }^{t} \mathrm{Bu}$ groups of 8 and 9 are too strong to be activated by the $\left({ }^{2} \mathrm{NAr}\right)$ and sterically restrict access to the $\left[\mathrm{Cu}_{2}\left(\mu^{2}-\mathrm{NAr}\right)\right]$ core. Furthermore, the anionic complexes $\mathbf{8}$ and $\mathbf{9}$ are less electrophilic and show diminished reactivity observed for the neutral analogues.

\section{CONCLUSIONS}

Neutral imido complexes of the type $\left({ }^{\mathrm{R}} \mathrm{dmx}\right) \mathrm{Cu}_{2}\left(\mu^{2}-\mathrm{NAr}\right)\left(\mathrm{R}\right.$ : Mes, ${ }^{t} \mathrm{Bu}$; $\mathrm{Ar}$ : 4-MeOC ${ }_{6} \mathrm{H}_{4}$, $\left.3,5-\left(\mathrm{F}_{3} \mathrm{C}\right)_{2} \mathrm{C}_{6} \mathrm{H}_{3}\right)$ were synthesized by treatment of the corresponding dicuprous precursors with aryl azides. Chemical reduction of the imido complexes afforded dicopper iminyl products as determined by EPR, $\mathrm{Cu} / \mathrm{N}$ XAS, crystallography, and computations. The iminyl ligand is distinct from previously reported subvalent nitrogen motifs which arise from radical delocalization following nitride, ${ }^{69,70}$ imide, ${ }^{31,44,45,71}$ or amide ${ }^{72-75}$ oxidation. ${ }^{72,76}$ The iminyl complexes reported herein show modest disruption of the aryl units, arising from population of the NAr lowest-lying $\pi^{*}$ orbital. The iminyl density is predominantly localized on the $\mathrm{N} 2 \mathrm{p}_{X}$ orbital, normal to the $\left[\mathrm{Cu}_{2}\left(\mu^{2}-\mathrm{NAr}\right)\right]$ plane, optimally located to aminate the benzylic $\mathrm{C}-\mathrm{H}$ bonds of the $\left({ }^{\mathrm{Mes}} \mathrm{dmx}\right)$ ligand but remain sterically occluded in the $\left({ }^{(B u} \mathrm{dmx}\right)$ framework and are thus robust. Despite the presence of bona fide radical character on the bridging iminyl, the $\left[\left({ }^{t B u} \mathrm{dmx}\right) \mathrm{Cu}_{2}\left(\mu^{2}-\mathrm{NAr}\right)^{-}\right.$complexes are resistant to 
nitrene transfer and $\mathrm{H}$ atom abstraction reactivity. Thus, while we were successful in generating dicopper complexes with substantive radical character accumulation at the bridgehead ligand, these complexes were found to be remarkably stable. Combined, our results contribute understanding of electronic structure, and identifying the precise localization of frontier orbital radical density, can aid in understanding group transfer reactions such as $\mathrm{C}-\mathrm{H}$ bond functionalization and nitrene insertion.

\section{Supplementary Material}

Refer to Web version on PubMed Central for supplementary material.

\section{ACKNOWLEDGMENTS}

We thank E. Johnson (Harvard) for helpful discussions and the initial synthesis of ( $\left.{ }^{\mathrm{Mes}} \mathrm{dmx}\right) \mathrm{H}_{2}$. We thank S. Sproules (Glasgow) for helpful guidance with EPR interpretation. T.A.B. gratefully acknowledges support by grants from NIH (GM-115815), the Dreyfus Foundation in the form of a Teacher-Scholar Award, and Harvard University. K.M.C. acknowledges the Fannie \& John Hertz Foundation and the National Science Foundation for financial support of this research. XAS data were obtained at SSRL, which is supported by the U.S. Department of Energy, Office of Science, Office of Basic Energy Sciences under Contract No. DE-AC02-76SF00515. The SSRL Structural Molecular Biology Program is supported by the Department of Energy's Office of Biological and Environmental Research, and by NIH/HIGMS (including P41GM103393). ChemMatCARS Sector 15 is principally supported by the National Science Foundation/Department of Energy under Grant No. NSF/CHE-0822838. Use of the Advanced Photon Source was supported by the U.S. Department of Energy, Office of Science, Office of Basic Energy Sciences, under Contract No. DE-AC02-06CH11357. Collection of low-temperature UV/vis spectra were obtained at the Center for Nanoscale Systems (CNS, Harvard University), a member of the National Nanotechnology Coordinated Infrastructure Network (NNCI), which is supported by the National Science Foundation under NSF award no. 1541959.

\section{REFERENCES}

(1). Labinger JA; Bercaw JE Understanding and Exploiting C-H Bond Activation. Nature 2002, 417, 507. [PubMed: 12037558]

(2). Godula K; Sames D C-H Bond Functionalization in Complex Organic Synthesis. Science 2006, 312, 67. [PubMed: 16601184]

(3). Bergman RG C-H Activation. Nature 2007, 446, 391. [PubMed: 17377575]

(4). Yamaguchi J; Yamaguchi AD; Itami K C-H Bond Functionalization: Emerging Synthetic Tools for Natural Products and Pharmaceuticals. Angew. Chem., Int. Ed 2012, 51, 8960.

(5). Badiei YM; Krishnaswamy A; Melzer MM; Warren TH Transient Terminal Cu-Nitrene Intermediates from Discrete Dicopper Nitrenes. J. Am. Chem. Soc 2006, 128, 15056. [PubMed: 17117834]

(6). Badiei YM; Dinescu A; Dai X; Palomino RM; Heinemann FW; Cundari TR; Warren TH Copper-Nitrene Complexes in Catalytic C-H Amination. Angew. Chem., Int. Ed 2008, 47, 9961.

(7). Aguila MJB; Badiei YM; Warren TH Mechanistic Insights into C-H Amination Via Dicopper Nitrenes. J. Am. Chem. Soc 2013, 135, 9399. [PubMed: 23656170]

(8). Bakhoda A; Jiang Q; Bertke JA; Cundari TR; Warren TH Elusive Terminal Copper Arylnitrene Intermediates. Angew. Chem., Int. Ed 2017, 56, 6426.

(9). Carsch KM; DiMucci IM; Iovan DA; Li A; Zheng S-L; Titus CJ; Lee SJ; Irwin KD; Nordlund D; Lancaster KM; Betley TA Synthesis of a Copper-Supported Triplet Nitrene Complex Pertinent to Copper-Catalyzed Amination. Science 2019, 365, 1138. [PubMed: 31515388]

(10). Groothaert MH; Smeets PJ; Sels BF; Jacobs PA; Schoonheydt RA Selective Oxidation of Methane by the Bis( $\mu$-oxo)Dicopper Core Stabilized on ZSM-5 and Mordenite Zeolites. J. Am. Chem. Soc. 2005, 127, 1394. [PubMed: 15686370] 
(11). Vanelderen P; Hadt RG; Smeets PJ; Solomon EI; Schoonheydt RA; Sels BF Cu-ZSM-5: A Biomimetic Inorganic Model for Methane Oxidation. J. Catal 2011, 284, 157. [PubMed: 23487537]

(12). Woertink JS; Smeets PJ; Groothaert MH; Vance MA; Sels BF; Schoonheydt RA; Solomon EIA $\left[\mathrm{Cu}_{2} \mathrm{O}\right]^{2+}$ Core in $\mathrm{Cu}-\mathrm{ZSM}-5$, the Active Site in the Oxidation of Methane to Methanol. Proc. Natl. Acad. Sci. U. S. A 2009, 106, 18908. [PubMed: 19864626]

(13). Johnson EJ; Kleinlein C; Musgrave RA; Betley TA Diiron Oxo Reactivity in a Weak-Field Environment. Chem. Sci 2019, 10, 6304. [PubMed: 31341583]

(14). Rosenthal J; Pistorio BJ; Chng LL; Nocera DG Aerobic Catalytic Photooxidation of Olefins by an Electron-Deficient Pacman Bisiron(III) $\mu$-oxo Porphyrin. J. Org. Chem 2005, 70, 1885. [PubMed: 15730314]

(15). Rosenthal J; Luckett TD; Hodgkiss JM; Nocera DG Photocatalytic Oxidation of Hydrocarbons by a Bis-Iron(III)- $\mu$-oxo Pacman Porphyrin Using $\mathrm{O}_{2}$ and Visible Light. J. Am. Chem. Soc 2006, 128, 6546. [PubMed: 16704240]

(16). Deng Y; Chang CJ; Nocera DG Direct Observation of the "Pac-Man" Effect from DibenzofUranBridged Cofacial Bisporphyrins. J. Am. Chem. Soc 2000, 122, 410.

(17). Wilding MJT; Iovan DA; Betley TA High-Spin Iron Imido Complexes Competent for C-H Bond Amination. J. Am. Chem. Soc 2017, 139, 12043. [PubMed: 28777558]

(18). Kleinlein C; Zheng S-L; Betley TA Ground State and Excited State Tuning in Ferric Dipyrrin Complexes Promoted by Ancillary Ligand Exchange. Inorg. Chem 2017, 56, 5892. [PubMed: 28437101]

(19). King ER; Sazama GT; Betley TA Co(III) Imidos Exhibiting Spin Crossover and C-H Bond Activation. J. Am. Chem. Soc 2012, 134, 17858. [PubMed: 23043624]

(20). Rieth RD; Mankad NP; Calimano E; Sadighi JP Palladium-Catalyzed Cross-Coupling of Pyrrole Anions with Aryl Chlorides, Bromides, and Iodides. Org. Lett 2004, 6, 3981. [PubMed: 15496079]

(21). Chang CJ; Deng Y; Heyduk AF; Chang CK; Nocera DG Xanthene-Bridged Cofacial Bisporphyrins. Inorg. Chem 2000, 39, 959. [PubMed: 12526375]

(22). Meyer EM; Gambarotta S; Floriani C; Chiesi-Villa A; Guastini C Polynuclear Aryl Derivatives of Group 11 Metals. Synthesis, Solid State-Solution Structural Relationship, and Reactivity with Phosphines. Organometallics 1989, 8, 1067.

(23). Pauling L The Nature of the Chemical Bond; Cornell University Press: Ithaca, NY, 1960; Vol. 260.

(24). Laitar DS Synthetic and catalytic studies of Group 11 N-heterocyclic carbene complexes Ph.D. Dissertation; Massachusetts Institute of Technology: Cambridge, MA, 2006.

(25). Walroth RC; Lukens JT; MacMillan SN; Finkelstein KD; Lancaster KM Spectroscopic Evidence for a $3 \mathrm{~d}^{10}$ Ground State Electronic Configuration and Ligand Field Inversion in $\left[\mathrm{Cu}\left(\mathrm{CF}_{3}\right)_{4}\right]^{1-} . \mathrm{J}$. Am. Chem. Soc. 2016, 138, 1922. [PubMed: 26844693]

(26). Walroth RC; Miles KC; Lukens JT; MacMillan SN; Stahl SS; Lancaster KM Electronic Structural Analysis of Copper(II)-TEMPO/ABNO Complexes Provides Evidence for Copper(I)oxoammonium Character. J. Am. Chem. Soc 2017, 139, 13507. [PubMed: 28921958]

(27). Walroth RC; Uebler JWH; Lancaster KM Probing Cui in Homogeneous Catalysis Using HighEnergy-Resolution Fluorescence-Detected X-Ray Absorption Spectroscopy. Chem. Commun 2015, 51, 9864.

(28). Tomson NC; Williams KD; Dai X; Sproules S; DeBeer S; Warren TH; Wieghardt K ReEvaluating the $\mathrm{Cu} \mathrm{K}$ Pre-Edge Xas Transition in Complexes with Covalent Metal-Ligand Interactions. Chem. Sci 2015, 6, 2474. [PubMed: 29308158]

(29). Kau LS; Spira-Solomon DJ; Penner-Hahn JE; Hodgson KO; Solomon EI X-Ray Absorption Edge Determination of the Oxidation State and Coordination Number of Copper. Application to the Type 3 Site in Rhus vernicifera Laccase and Its Reaction with Oxygen. J. Am. Chem. Soc 1987, 109, 6433.

(30). George SJ; Lowery MD; Solomon EI; Cramer SP Copper L-Edge Spectral Studies: A Direct Experimental Probe of the Ground-State Covalency in the Blue Copper Site in Plastocyanin. J. Am. Chem. Soc 1993, 115, 2968. 
(31). Wilding MJT; Iovan DA; Wrobel AT; Lukens JT; MacMillan SN; Lancaster KM; Betley TA Direct Comparison of C-H Bond Amination Efficacy through Manipulation of NitrogenValence Centered Redox: Imido Versus Iminyl. J. Am. Chem. Soc 2017, 139, 14757. [PubMed: 28937756]

(32). Dong Y; Lukens J; Clarke RM; Zheng S-L; Lancaster K; Betley T Synthesis, Characterization and C-H Amination Reactivity of Nickel Iminyl Complexes. Chem. Sci 2020, Advance Article DOI: $10.1039 / \mathrm{C} 9 \mathrm{SC} 04879 \mathrm{~K}$.

(33). Wigley DE Organoimido Complexes of the Transition Metals In Prog. Inorg. Chem; Karlin KD, Ed.; Wiley: Berlin, 2007; Vol. 42, pp 239-482.

(34). Nugent WA; Haymore BL Transition Metal Complexes Containing Organoimido (NR) and Related Ligands. Coord. Chem. Rev 1980, 31, 123.

(35). Wiese S; McAfee JL; Pahls DR; McMullin CL; Cundari TR; Warren TH C-H Functionalization Reactivity of a Nickel-Imide. J. Am. Chem. Soc 2012, 134, 10114. [PubMed: 22616768]

(36). Laskowski CA; Miller AJM; Hillhouse GL; Cundari TR A Two-Coordinate Nickel Imido Complex That Effects C-H Amination. J. Am. Chem. Soc 2011, 133, 771. [PubMed: 21175213]

(37). Berry JF Terminal Nitrido and Imido Complexes of the Late Transition Metals. Comments Inorg. Chem 2009, 30, 28.

(38). Desnoyer AN; Love JA Recent Advances in Well-Defined, Late Transition Metal Complexes That Make and/or Break C-N, C-O and C-S Bonds. Chem. Soc. Rev 2017, 46, 197. [PubMed: 27849097]

(39). Kogut E; Wiencko HL; Zhang L; Cordeau DE; Warren TH A Terminal Ni(III)—Imide with Diverse Reactivity Pathways. J. Am. Chem. Soc 2005, 127, 11248. [PubMed: 16089446]

(40). Baek Y; Betley TA Catalytic C-H Amination Mediated by Dipyrrin Cobalt Imidos. J. Am. Chem. Soc 2019, 141, 7797. [PubMed: 31016975]

(41). Dai X; Warren TH Discrete Bridging and Terminal Copper Carbenes in Copper-Catalyzed Cyclopropanation. J. Am. Chem. Soc 2004, 126, 10085. [PubMed: 15303885]

(42). Decker A; Fenske D; Maczek K New Imido-Bridged Transition Metal Clusters: $\left[\left(\mathrm{C}_{5} \mathrm{H}_{5}\right)_{4} \mathrm{Ti}_{4}\left(\mathrm{NSnMe}_{3}\right)_{4}\right],\left[\mathrm{Co}_{11}\left(\mathrm{PPh}_{3}\right)_{3}(\mathrm{NPh})_{12}\right],\left[\mathrm{Ni}_{11} \mathrm{Br}_{6}\left(\mathrm{~N}^{t} \mathrm{Bu}\right)_{8}\right]$, and [Li(thf $\left.)_{4}\right]_{4}\left[\mathrm{Cu}_{24}(\mathrm{NPh})_{14}\right]$. Angew. Chem., Int. Ed. Engl 1996, 35, 2863.

(43). Reiß P; Fenske D Neue Amido- Und Imidoverbrückte Kupferkomplexe - Synthesen Und Strukturen Von $\left.\left[\left\{\mathrm{Li}_{(\mathrm{OEt}}\right)_{2}\right\}_{2}\right]-\left[\mathrm{Cu}\left(\mathrm{NPh}_{2}\right)_{3}\right],\left[\mathrm{ClCuN}\left(\mathrm{SnMe}_{3}\right)_{3}\right],\left[\left\{\mathrm{CuN}\left(\mathrm{SnMe}_{3}\right)_{2}\right\}_{4}\right]$, $\left[\mathrm{Cu}_{16}\left(\mathrm{NH}_{2}{ }^{t} \mathrm{Bu}\right)_{12} \mathrm{Cl}_{16}\right],\left[\left\{\mathrm{CuNH}{ }^{t} \mathrm{Bu}\right\}_{8}\right]$, [Li(dme) $\left.)_{3}\right]\left[\mathrm{Cu} 6-(\mathrm{NHMes})_{3}(\mathrm{NMes})_{2}\right],\left[\mathrm{PPh}_{3}\left(\mathrm{C}_{6} \mathrm{H}_{4}\right)\right.$ CuNHMes], [\{[Li(dme) $\left.][\mathrm{Cu}-(\mathrm{NHMes})(\mathrm{NHPh})]\}_{2}\right]$ Und $\left[\left\{\mathrm{Li}(\mathrm{dme})_{3}\right\}_{3}\right]\left[\mathrm{Li}(\mathrm{dme})_{2}\right]\left[\mathrm{Cu}_{12}(\mathrm{NPh})_{8}\right]$. Z. Anorg. Allg. Chem 2000, 626, 1317.

(44). Iovan DA; Betley TA Characterization of Iron-Imido Species Relevant for N-Group Transfer Chemistry. J. Am. Chem. Soc 2016, 138, 1983. [PubMed: 26788747]

(45). King ER; Hennessy ET; Betley TA Catalytic C-H Bond Amination from High-Spin Iron Imido Complexes. J. Am. Chem. Soc 2011, 133, 4917. [PubMed: 21405138]

(46). DeBeer George S; Neese F Calibration of Scalar Relativistic Density Functional Theory for the Calculation of Sulfur K-Edge X-Ray Absorption Spectra. Inorg. Chem 2010, 49, 1849. [PubMed: 20092349]

(47). DeBeer George S; Petrenko T; Neese F Time-Dependent Density Functional Calculations of Ligand K-Edge X-Ray Absorption Spectra. Inorg. Chim. Acta 2008, 361, 965.

(48). Lukens JT; DiMucci IM; Kurogi T; Mindiola DJ; Lancaster KM Scrutinizing Metal-Ligand Covalency and Redox Non-Innocence Via Nitrogen K-Edge X-Ray Absorption Spectroscopy Chem. Sci 2019, 10, 5044. [PubMed: 31183055]

(49). Neese F Definition of Corresponding Orbitals and the Diradical Character in Broken Symmetry DFT Calculations on Spin Coupled Systems. J. Phys. Chem. Solids 2004, 65, 781.

(50). CAS $(11,9)$ calculations were carried out on the monoanions, although these were found to have effectively single-configurational ground states, so results of hybrid DFT single-point calculations were used to describe these complexes.

(51). LeCloux DD; Davydov R; Lippard SJ Synthesis and Characterization of Spin-Delocalized Carboxylate-Bridged $\mathrm{Cu}(\mathrm{I})-\mathrm{Cu}(\mathrm{II})$ Mixed-Valence Complexes Having Only Oxygen Donor Ligands. J. Am. Chem. Soc 1998, 120, 6810. 
(52). Barr ME; Smith PH; Antholine WE; Spencer B Crystallographic, Spectroscopic and Theoretical Studies of an Electron-Deiocalized $\mathrm{Cu}(1.5)-\mathrm{Cu}(1.5)$ Complex. J. Chem. Soc. Chem. Commun 1993, 1649.

(53). Gupta R; Zhang ZH; Powell D; Hendrich MP; Borovik A Synthesis and Characterization of Completely Delocalized Mixed- Valent Dicopper Complexes. Inorg. Chem 2002, 41, 5100. [PubMed: 12354043]

(54). Robin MB; Day P Mixed Valence Chemistry - A Survey and Classification In Adv. Inorg. Chem. Rad; Emeléus HJ, Sharpe AG, Eds.; Elsevier: Amsterdam, 1968; Vol. 10, pp 247-422.

(55). Goodman B; Raynor J Electron Spin Resonance of Transition Metal Complexes In Adv. Inorg. Chem. Rad; Emeléus HJ, Sharpe AG, Eds.; Elsevier: Amsterdam, 1970; Vol. 13, pp 135-362.

(56). Demadis KD; Hartshorn CM; Meyer TJ The Localized- to-Delocalized Transition in MixedValence Chemistry. Chem. Rev 2001, 101, 2655. [PubMed: 11749392]

(57). Gagne RR; Koval CA; Smith TJ; Cimolino MC Binuclear Complexes of Macrocyclic Ligands. Electrochemical and Spectral Properties of Homobinuclear $\mathrm{Cu}^{\mathrm{II}} \mathrm{Cu}^{\mathrm{II}}, \mathrm{Cu}^{\mathrm{II}} \mathrm{Cu}^{\mathrm{I}}$, and $\mathrm{Cu}^{\mathrm{I}} \mathrm{Cu}^{\mathrm{I}}$ Species Including an Estimated Intramolecular Electron Transfer Rate. J. Am. Chem. Soc 1979, 101, 4571.

(58). Long RC; Hendrickson DN Intramolecular Electron Transfer in a Series of Mixed-Valence Copper(II)-Copper(I) Complexes. J. Am. Chem. Soc 1983, 105, 1513.

(59). Ziegler MS; Levine DS; Lakshmi K; Tilley TD Aryl Group Transfer from Tetraarylborato Anions to an Electrophilic Dicopper(I) Center and Mixed-Valence $\mu$-Aryl Dicopper(I,II) Complexes. J. Am. Chem. Soc 2016, 138, 6484. [PubMed: 27176131]

(60). Brunold TC; Gamelin DR; Solomon EI Excited-State Exchange Coupling in Bent Mn(III) $-\mathrm{O}-\mathrm{Mn}(\mathrm{III})$ Complexes: Dominance of the $\pi / \sigma$ Superexchange Pathway and Its Possible Contributions to the Reactivities of Binuclear Metalloproteins. J. Am. Chem. Soc 2000, 122, 8511.

(61). Brunschwig BS; Creutz C; Sutin N Optical Transitions of Symmetrical Mixed-Valence Systems in the Class II-III Transition Regime. Chem. Soc. Rev 2002, 31 , 168. [PubMed: 12122642]

(62). Solomon EI; Heppner DE; Johnston EM; Ginsbach JW; Cirera J; Qayyum M; Kieber-Emmons MT; Kjaergaard CH; Hadt RG; Tian L Copper Active Sites in Biology. Chem. Rev. 2014, 114, 3659. [PubMed: 24588098]

(63). Harkins SB; Mankad NP; Miller AJM; Szilagyi RK; Peters JC Probing the Electronic Structures of $\left[\mathrm{Cu}_{2}\left(\mu-\mathrm{XR}_{2}\right)\right]^{\mathrm{n}+}$ Diamond Cores as a Function of the Bridging $\mathrm{X}$ Atom $(\mathrm{X}=\mathrm{N}$ or $\mathrm{P})$ and Charge $(n=0,1,2)$. J. Am. Chem. Soc 2008, 130, 3478. [PubMed: 18298114]

(64). Mankad NP; Harkins SB; Antholine WE; Peters JC Multifrequency EPR Studies of $\left[\mathrm{Cu}^{1.5} \mathrm{Cu}^{1.5}\right]+$ for $\mathrm{Cu}_{2}\left(\mu-\mathrm{NR}_{2}\right)_{2}$ and $\mathrm{Cu}_{2}\left(\mu-\mathrm{NR}_{2}\right)_{2}$ Diamond Cores. Inorg. Chem 2009, 48, 7026. [PubMed: 19572723]

(65). Harkins SB; Peters JC Amido-Bridged $\mathrm{Cu}_{2} \mathrm{~N}_{2}$ Diamond Cores That Minimize Structural Reorganization and Facilitate Reversible Redox Behavior between a $\mathrm{Cu}^{\mathrm{I}} \mathrm{Cu}^{\mathrm{I}}$ and a Class III Delocalized $\mathrm{Cu}^{1.5} \mathrm{Cu}^{1.5}$ Species. J. Am. Chem. Soc 2004, 126, 2885. [PubMed: 14995206]

(66). DeBeer George S; Metz M; Szilagyi RK; Wang H; Cramer SP; Lu Y; Tolman WB; Hedman B; Hodgson KO; Solomon EI A Quantitative Description of the Ground-State Wave Function of $\mathrm{Cu}_{\mathrm{A}}$ by X-Ray Absorption Spectroscopy: Comparison to Plastocyanin and Relevance to Electron Transfer. J. Am. Chem. Soc 2001, 123, 5757. [PubMed: 11403610]

(67). Houser RP; Young VG; Tolman WB A Thiolate-Bridged, Fully Delocalized Mixed-Valence Dicopper(I,II) Complex That Models the CuA Biological Electron-Transfer Site. J. Am. Chem. Soc 1996, 118, 2101.

(68). Takaoka A; Moret M-E; Peters JC A Ru(I) Metalloradical That Catalyzes Nitrene Coupling to Azoarenes from Arylazides. J. Am. Chem. Soc 2012, 134, 6695. [PubMed: 22381423]

(69). Gloaguen Y; Rebreyend C; Lutz M; Kumar P; Huber M; van der Vlugt JI; Schneider S; de Bruin B An Isolated Nitridyl Radical-Bridged $\{\mathrm{Rh}(\mathrm{N}) \mathrm{Rh}\}$ Complex. Angew. Chem. Int. Ed 2014, 53, 6814.

(70). Tran BL; Washington MP; Henckel DA; Gao X; Park H; Pink M; Mindiola DJ A Four Coordinate Parent Imide via a Titanium Nitridyl. Chem. Commun 2012, 48, 1529. 
(71). Lyaskovskyy V; Suarez AIO; Lu H; Jiang H; Zhang XP; de Bruin B Mechanism of Cobalt(II) Porphyrin-Catalyzed C-H Amination with Organic Azides: Radical Nature and H-Atom Abstraction Ability of the Key Cobalt(III)-Nitrene Intermediates. J. Am. Chem. Soc 2011, 133, 12264. [PubMed: 21711027]

(72). Mankad NP; Antholine WE; Szilagyi RK; Peters JC Three-Coordinate Copper(I) Amido and Aminyl Radical Complexes. J. Am. Chem. Soc 2009, 131, 3878. [PubMed: 19253942]

(73). Büttner T; Geier J; Frison G; Harmer J; Calle C; Schweiger A; Schönberg H; Grützmacher H A Stable Aminyl Radical Metal Complex. Science 2005, 307, 235. [PubMed: 15653498]

(74). Adhikari D; Mossin S; Basuli F; Huffman JC; Szilagyi RK ; Meyer K; Mindiola DJ Structural, Spectroscopic, and Theoretical Elucidation of a Redox-Active Pincer-Type Ancillary Applied in Catalysis. J. Am. Chem. Soc 2008, 130, 3676. [PubMed: 18302384]

(75). Rodríguez-Lugo RE; de Bruin B; Trincado M; Grützmacher H A Stable Aminyl Radical Coordinated to Cobalt. Chem. - Eur. J 2017, 23, 6795. [PubMed: 28164405]

(76). Suarez AIO; Lyaskovskyy V; Reek JNH; van der Vlugt JI; de Bruin B Complexes with NitrogenCentered Radical Ligands: Classification, Spectroscopic Features, Reactivity, and Catalytic Applications. Angew. Chem. Int. Ed 2013, 52, 12510. 


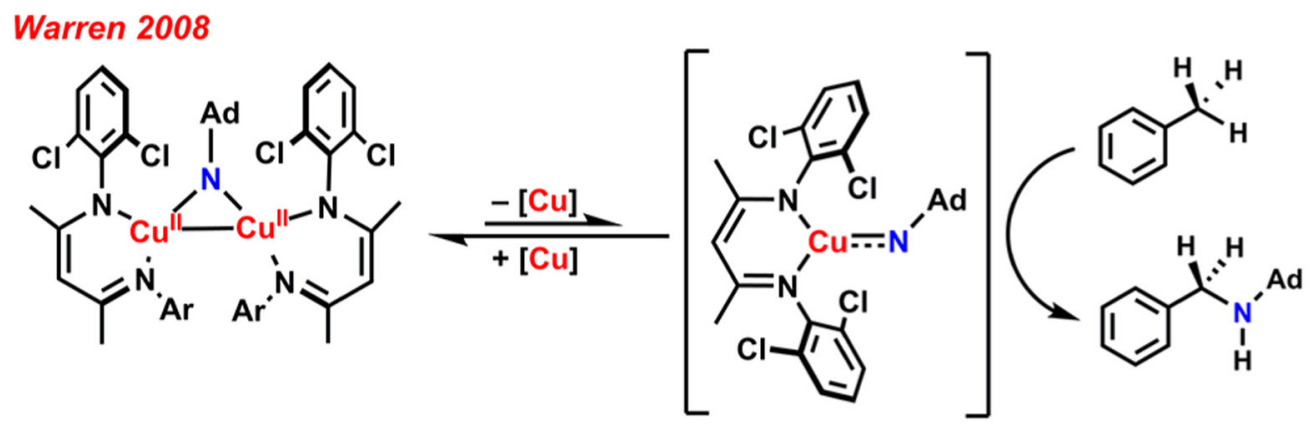

Solomon 2009

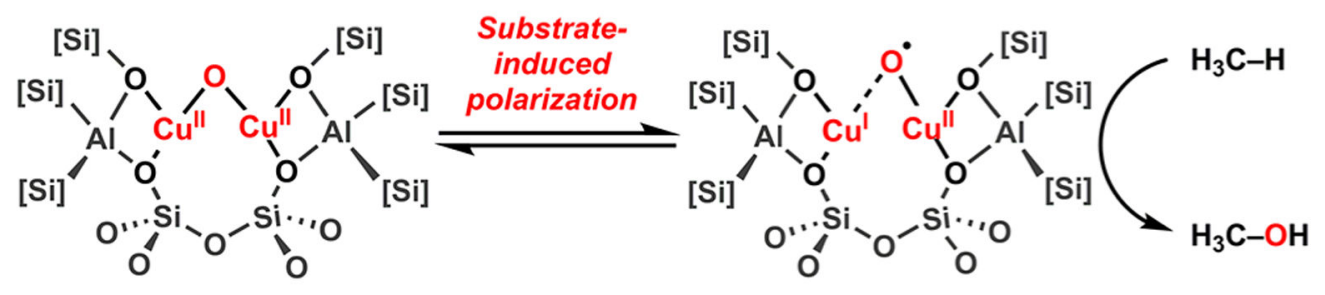

This work

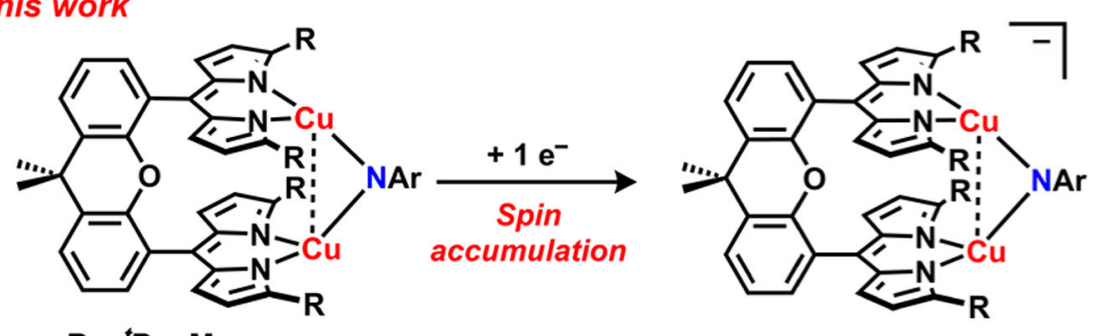

Figure 1.

Dicopper mediated $\mathrm{C}-\mathrm{H}$ bond functionalization: (top) monomer-dimer imido equilibrium for alkane amination (Warren); (middle) $\left[\mathrm{Cu}_{2}\left(\mu^{2}-\mathrm{O}\right)\right]$ polarization for methane hydroxylation (Solomon); (bottom) radical accumulation on imido bridge for $\left[\mathrm{Cu}_{2}\left(\mu^{2}-\mathrm{NR}\right)\right]^{-}$(this work). 

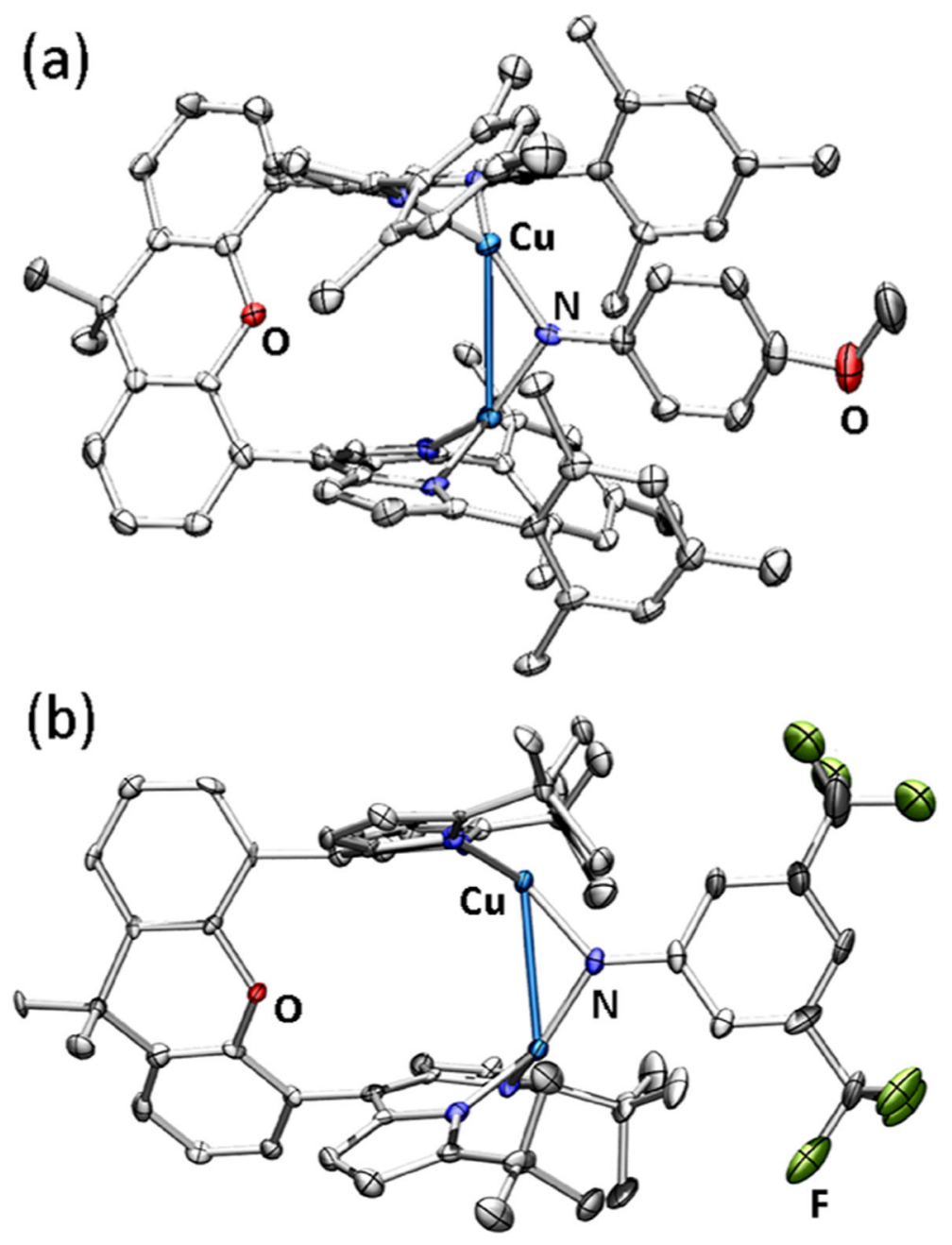

Figure 2.

Solid state molecular structures of (a) $\left({ }^{\mathrm{Mes}} \mathrm{dmx}\right) \mathrm{Cu}_{2}\left(\mu^{2}-\mathrm{N}\left(\mathrm{C}_{6} \mathrm{H}_{4} \mathrm{OMe}\right)\right)$ (2) and (b) $\left.{ }^{\left({ }^{B B u}\right.} \mathrm{dmx}\right) \mathrm{Cu}_{2}\left(\mu^{2}-\mathrm{N}\left(3,5-\left(\mathrm{F}_{3} \mathrm{C}\right)_{2} \mathrm{C}_{6} \mathrm{H}_{3}\right)\right)(6)$ at $50 \%$ ellipsoid probability. Color scheme: $\mathrm{Cu}$ (cobalt blue), F (yellow-green), N (blue), and O (red). Solvent molecules, solid-state disorder, and hydrogen atoms are omitted for clarity. 

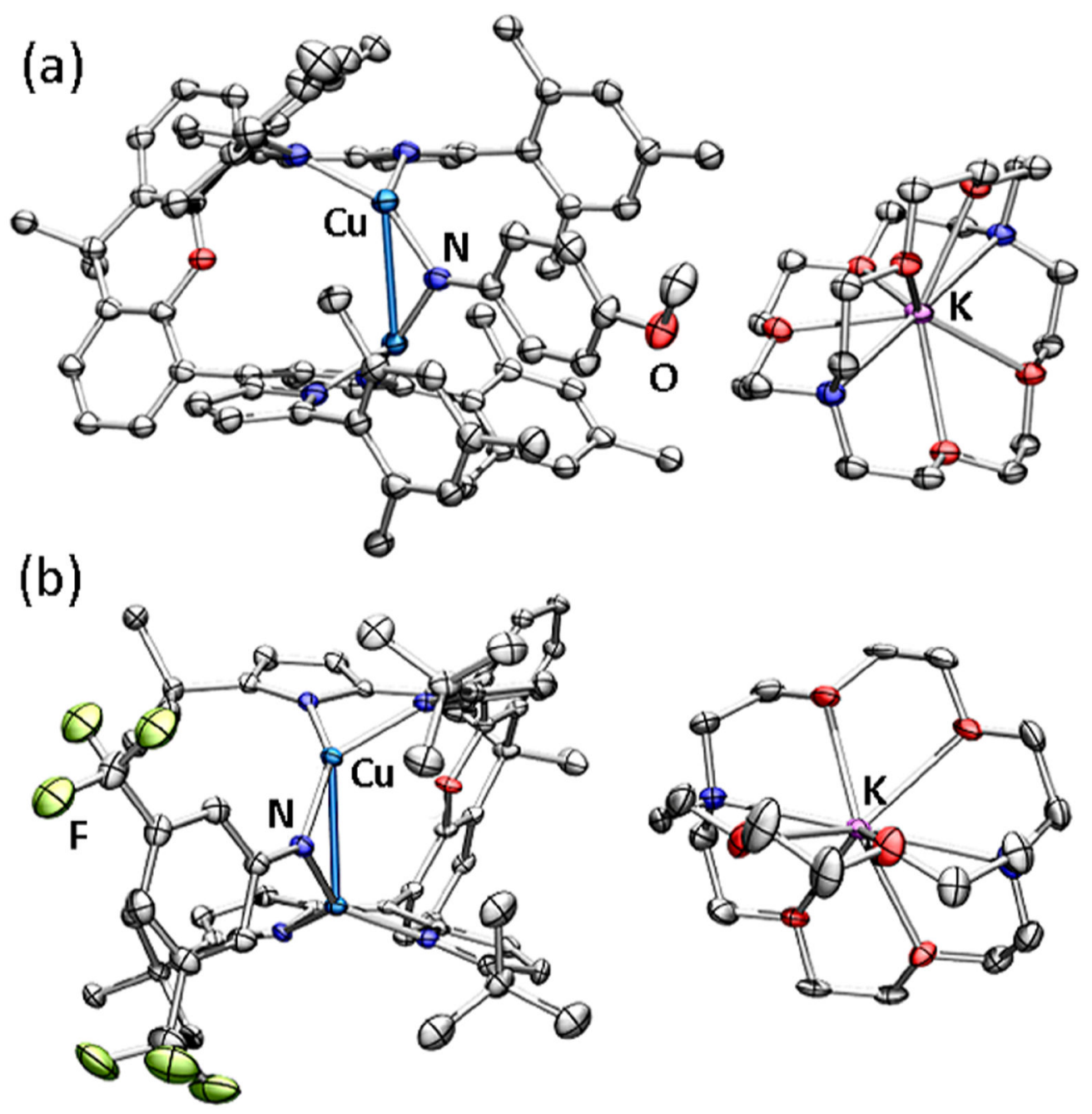

Figure 3.

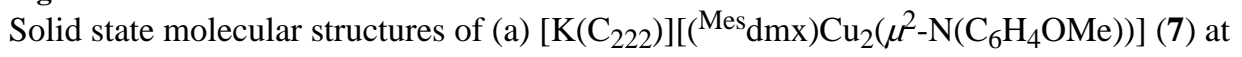
$35 \%$ ellipsoid probability and (b) $\left[\mathrm{K}\left(\mathrm{C}_{222}\right)\right]\left[\left({ }^{(\mathrm{Bu}} \mathrm{dmx}\right) \mathrm{Cu}_{2}\left(\mu^{2}-\mathrm{N}\left(3,5-\left(\mathrm{F}_{3} \mathrm{C}\right)_{2} \mathrm{C}_{6} \mathrm{H}_{3}\right)\right)\right](9)$ at $50 \%$ ellipsoid probability. Color scheme: $\mathrm{Cu}$ (cobalt blue), $\mathrm{F}$ (yellow-green), $\mathrm{N}$ (blue), $\mathrm{O}$ (red), and K (pink). Solvent molecules, solid-state disorder, and hydrogen atoms are omitted for clarity. 

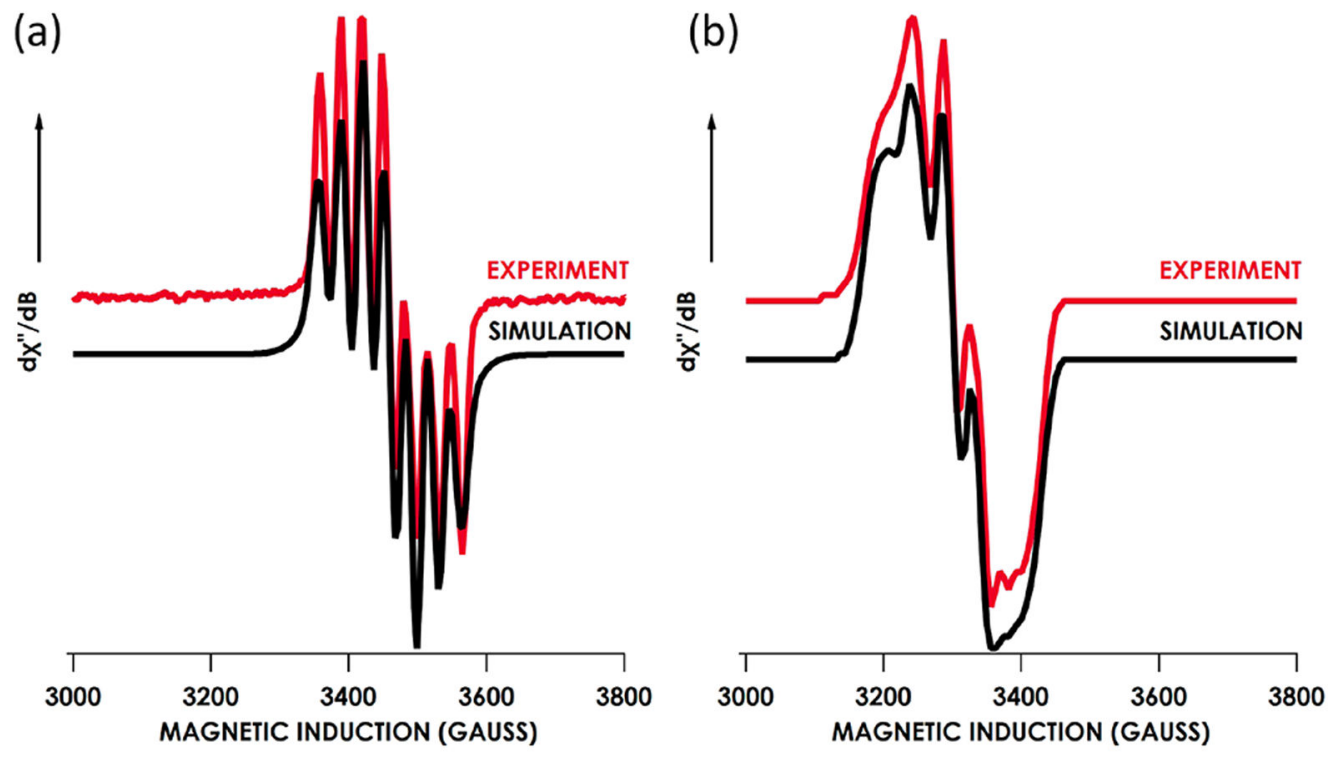

Figure 4.

(a) Solution 2-methyltetrahydrofuran $(9.843 \mathrm{GHz})$ EPR spectrum of 7 obtained at $298 \mathrm{~K}$ expanded to show an isotropic $S=1 / 2$ signal (red) simulated (black) with the following parameters: $g_{\text {iso }}=2.033, \sigma g_{X}=0.0277, \sigma g_{y}=0.0039, \sigma g_{z}=0.0051 ;{ }^{63} \mathrm{Cu}_{2} A_{\text {iso }}=87.4$ $\mathrm{MHz} ;{ }^{14} \mathrm{~N} A_{\text {iso }}=17.8 \mathrm{MHz}$. (b) Frozen 2-methyltetrahydrofuran $(9.378 \mathrm{GHz})$ EPR spectrum 7 obtained at $4 \mathrm{~K}$ expanded to show an anisotropic $S=1 / 2$ signal (red) simulated (black) with the following parameters: $g_{X}=1.979, g_{y}=2.032, g_{z}=2.074 ; \sigma g_{X}=0.0080, \sigma g_{y}=$ $0.0014, \sigma g_{z}=0.0098 ;{ }^{63} \mathrm{Cu}_{2} A_{X}=9.3 \mathrm{MHz}, A_{y}=43.9 \mathrm{MHz}, A_{Z}=9.7 \mathrm{MHz} ;{ }^{14} \mathrm{~N} A_{X}=86.6$ $\mathrm{MHz}, A_{y}=125.6 \mathrm{MHz}, A_{z}=130.3 \mathrm{MHz}$. 

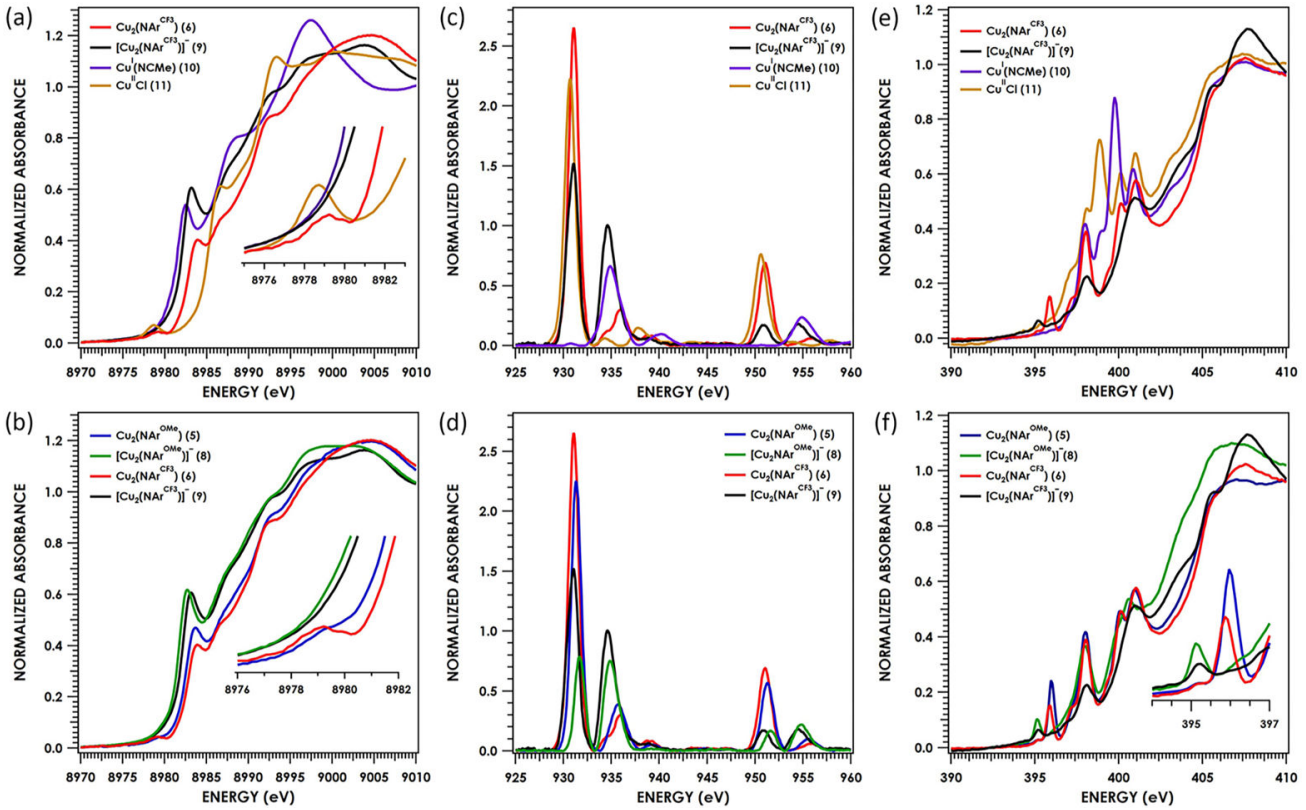

Figure 5.

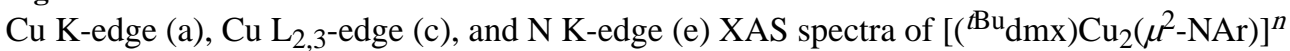
for $n=0$, Ar: 3,5- $\left(\mathrm{CF}_{3}\right)_{2}-\mathrm{C}_{6} \mathrm{H}_{3}(6$, red $) ; n=-1$, Ar: 3,5- $\left(\mathrm{F}_{3} \mathrm{C}\right)_{2} \mathrm{C}_{6} \mathrm{H}_{3}(\mathbf{9}$, black); and mononuclear $\left({ }^{t \mathrm{Bu}} \mathrm{L}\right) \mathrm{Cu}^{\mathrm{I}}(\mathrm{NCMe})\left(\mathbf{1 0}\right.$, purple); $\left({ }^{\left({ }^{\mathrm{Bu}} \mathrm{L}\right.}\right) \mathrm{Cu}^{\mathrm{II}} \mathrm{Cl}(\mathbf{1 1}$, gold); $\mathrm{Cu}$ K-edge (b), $\mathrm{Cu}$ $\mathrm{L}_{2,3}$-edge (d), and N K-edge (f) XAS spectra of $\left[\left({ }^{\left({ }^{B u} \mathrm{dmx}\right.}\right) \mathrm{Cu}_{2}\left(\mu^{2}-\mathrm{NAr}\right)\right]^{n}$ for $n=0$, Ar: 4$\mathrm{MeOC}_{6} \mathrm{H}_{4}\left(\mathbf{5}\right.$, blue); Ar: 3,5- $\left(\mathrm{F}_{3} \mathrm{C}\right)_{2} \mathrm{C}_{6} \mathrm{H}_{3}\left(\mathbf{6}\right.$, red); for $n=-1$, Ar: 4- $\mathrm{MeOC}_{6} \mathrm{H}_{4}(\mathbf{8}$, green); Ar: 3,5- $\left(\mathrm{F}_{3} \mathrm{C}\right)_{2} \mathrm{C}_{6} \mathrm{H}_{3}(\mathbf{9}$, black). 


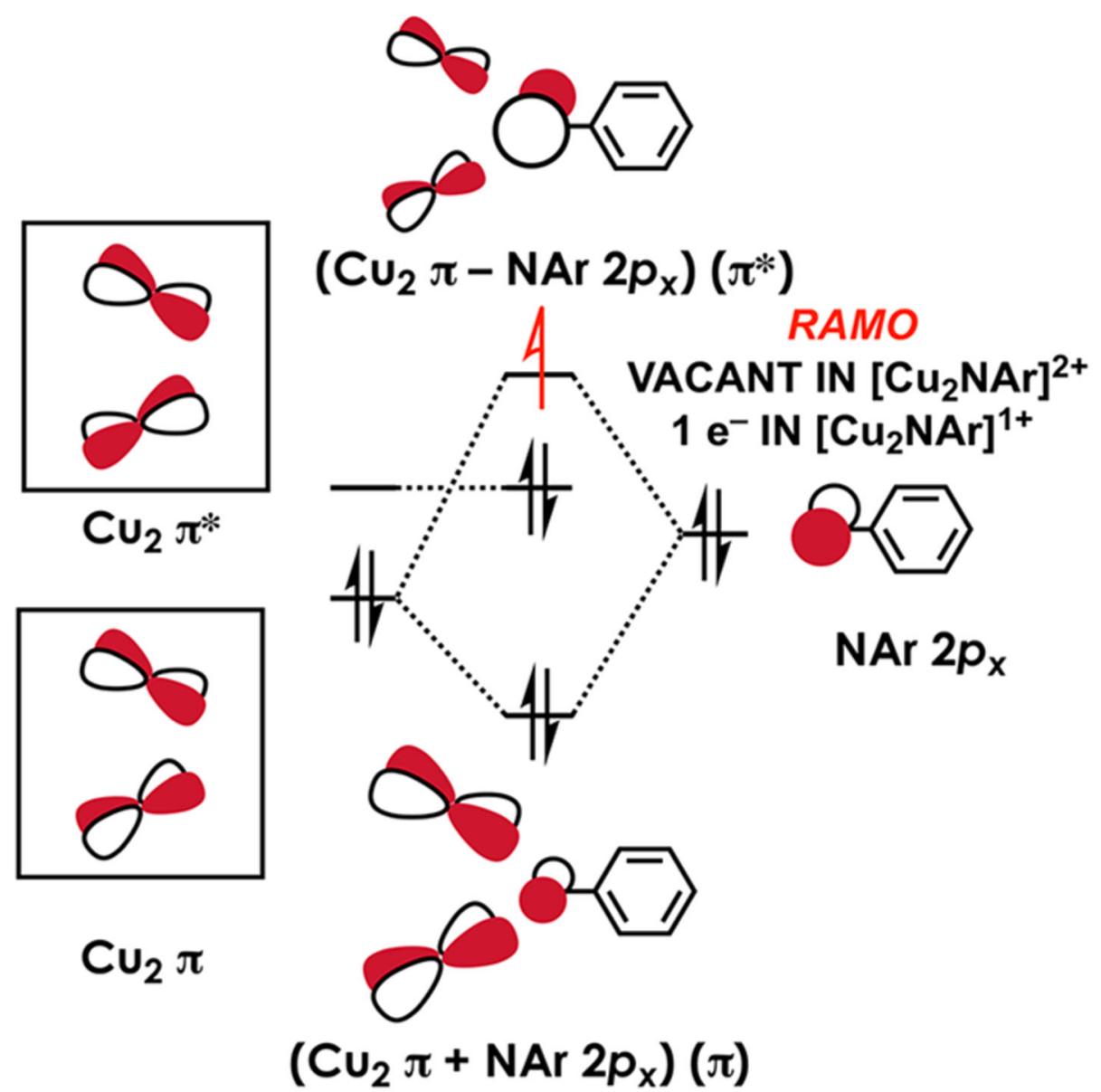

Figure 6.

Simplified qualitative frontier molecular orbital framework in idealized $\mathrm{C}_{2 V}$ symmetry showcasing $\mathrm{Cu}_{2}-\mathrm{NAr} \pi$ bonding in $\mathbf{5 / 6}$ and $\mathbf{8} / \mathbf{9}$. 


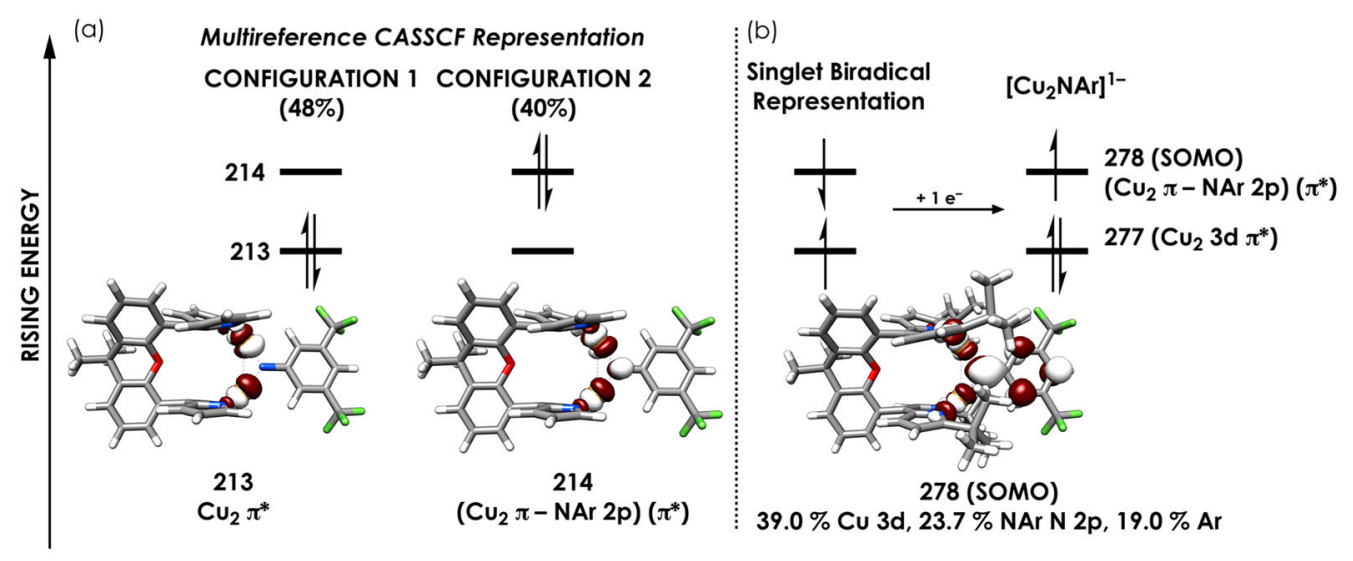

Figure 7.

(a) Two leading configurations making up the singlet ground state resulting from a CAS $(10,9)$ calculation using the truncated model $\left[\left({ }^{t \mathrm{Bu}} \mathrm{dmx}\right) \mathrm{Cu}_{2}\left(\mu^{2}-\mathrm{N}\left(3,5-\left(\mathrm{F}_{3} \mathrm{C}\right)_{2} \mathrm{C}_{6} \mathrm{H}_{3}\right)\right)\right]^{n}(n$ $\left.=0, \mathbf{6}^{\prime}\right)$. These calculations employed the ZORA-def2-TZVP $(-\mathrm{f})$ basis set on $\mathrm{Cu}$ and $\mathrm{N}$ with the ZORA-def2-SVP basis set on all other atoms. Occupation of MOs 213 and 214 differentiates the two configurations; these orbitals are printed beneath the diagram. Panel $b$ depicts the single configuration defining the doublet ground state of $\mathbf{9}$. The MOs comprise QROs generated produced following an unrestricted B3LYP calculation employing the $\mathrm{CP}(\mathrm{PPP})$ basis set on $\mathrm{Cu}$ and def2-TZVP $(-\mathrm{f})$ on all other atoms. Orbital plots are depicted at an isovalue of $0.03 \mathrm{au}$. All orbital labels are based on dominant interaction(s). 


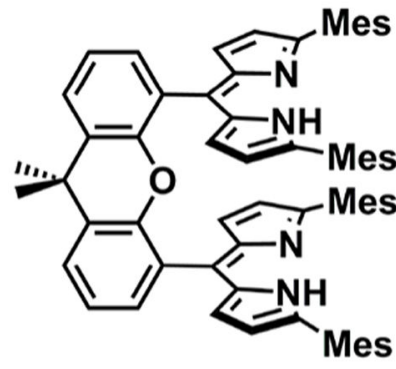

( $\left.{ }^{\text {Mes }} \mathrm{dmx}\right) \mathrm{H}_{2}$

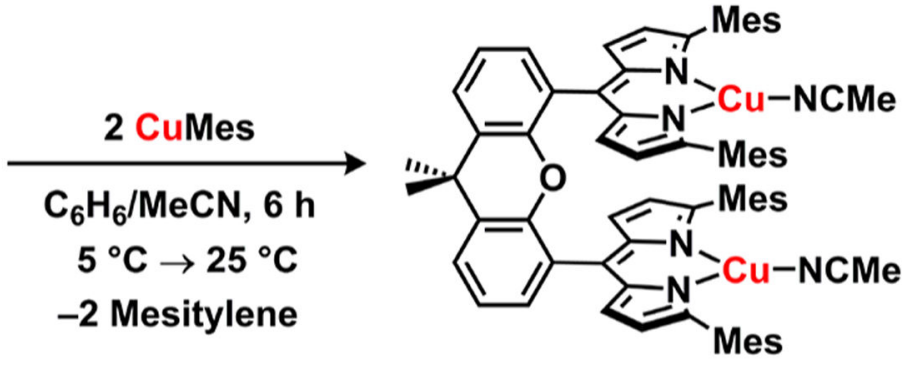

(1)

Scheme 1 


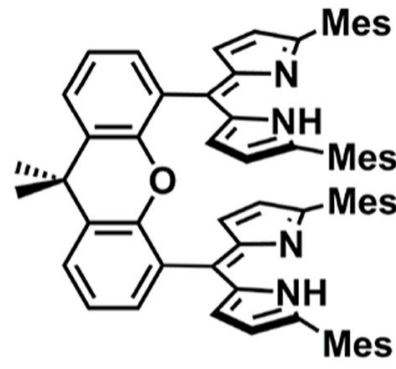

( $\left.{ }^{\text {Mes }} \mathrm{dmx}\right) \mathrm{H}_{2}$

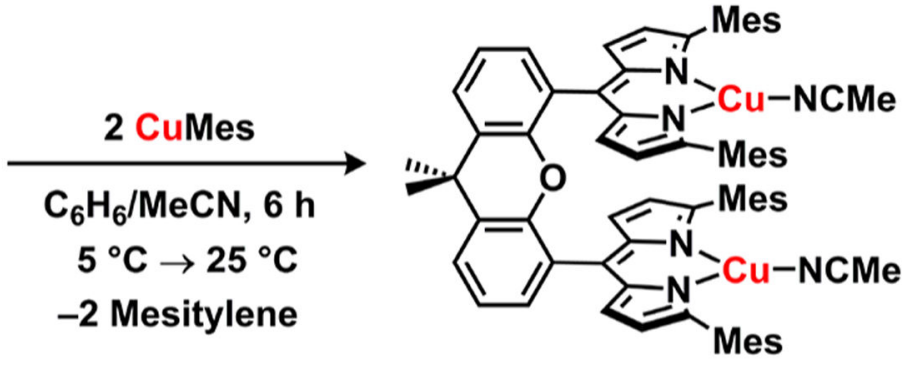

(1)

Scheme 2 


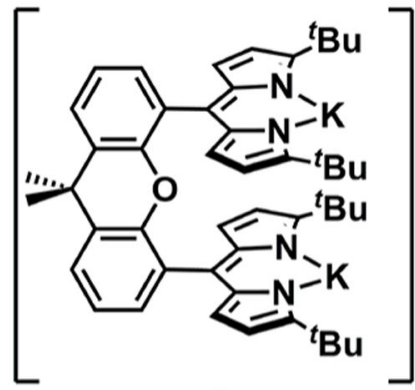

(4)

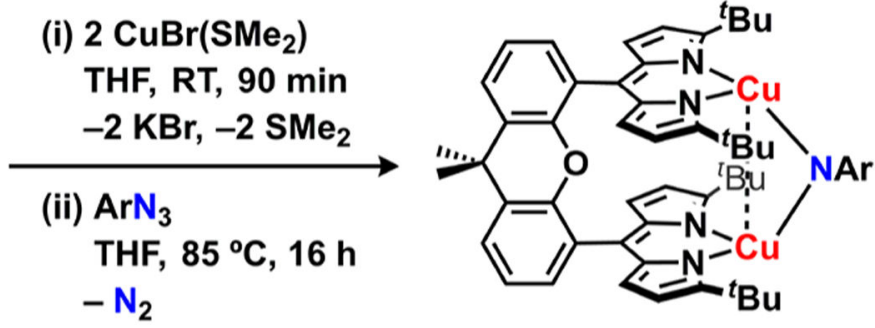

(5): $\mathrm{Ar}=4-\mathrm{MeOC}_{6} \mathrm{H}_{4}$ (6): $\mathrm{Ar}=3,5-\left(\mathrm{F}_{3} \mathrm{C}\right)_{2} \mathrm{C}_{6} \mathrm{H}_{3}$

Scheme 3 


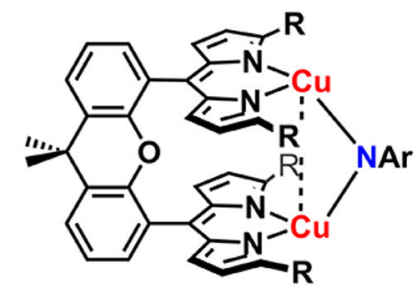

(R,Ar) (2): Mes, 4-MeOC $6 \mathrm{H}_{4}$

(5): ${ }^{\mathrm{t}} \mathrm{Bu}, 4-\mathrm{MeOC}_{6} \mathrm{H}_{4}$

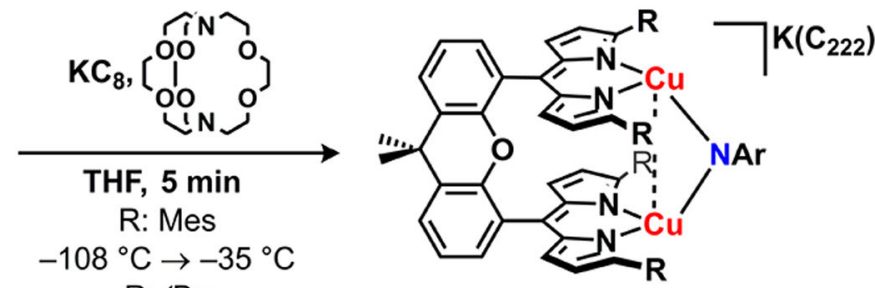

(6): ${ }^{t} \mathrm{Bu}, 3,5-\left(\mathrm{F}_{3} \mathrm{C}\right)_{2} \mathrm{C}_{6} \mathrm{H}_{3}$

$5^{\circ} \mathrm{C} \rightarrow 25^{\circ} \mathrm{C}$

(R,Ar) (7): Mes, 4-MeOC $6 \mathrm{H}_{4}$

(8): ${ }^{\mathrm{t}} \mathrm{Bu}, 4-\mathrm{MeOC}_{6} \mathrm{H}_{4}$

(9): ${ }^{t} \mathrm{Bu}, 3,5-\left(\mathrm{F}_{3} \mathrm{C}\right)_{2} \mathrm{C}_{6} \mathrm{H}_{3}$

Scheme 4 


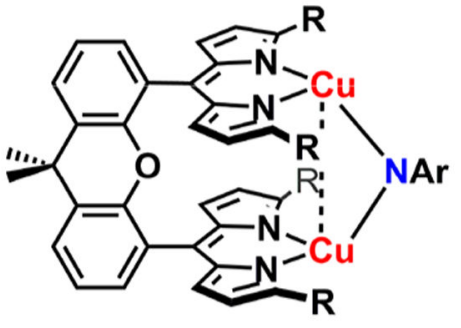

(Ar) 4- $\mathrm{MeOC}_{6} \mathrm{H}_{4}(\mathbf{2}, \mathbf{5})$

$3,5-\left(\mathrm{F}_{3} \mathrm{C}\right)_{2} \mathrm{C}_{6} \mathrm{H}_{3}(3,6)$

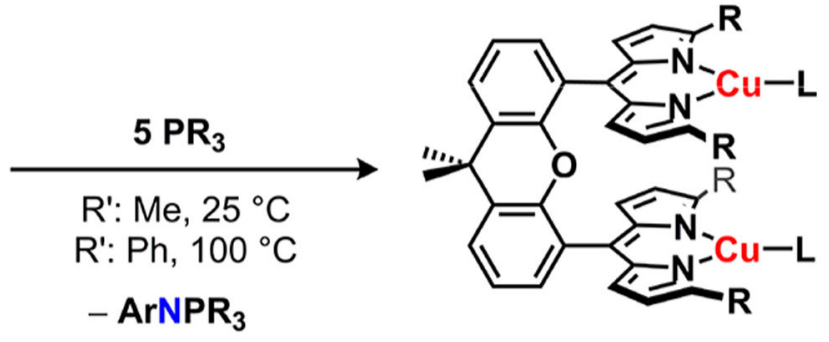

(R, L) (12): Mes, $\mathrm{PMe}_{3}$ (13): ${ }^{t} \mathrm{Bu}, \mathrm{PPh}_{3}$

Scheme 5 


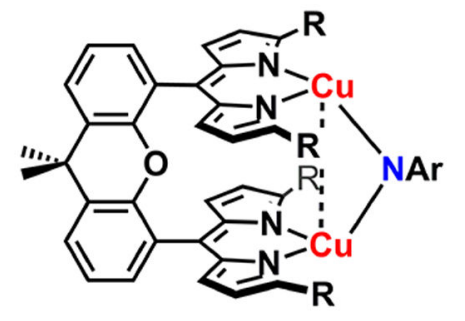

(Ar) 4- $\mathrm{MeOC}_{6} \mathrm{H}_{4}(\mathbf{2}, \mathbf{5})$ $3,5-\left(\mathrm{F}_{3} \mathrm{C}\right)_{2} \mathrm{C}_{6} \mathrm{H}_{3}(\mathbf{3}, \mathbf{6})$

Scheme 6

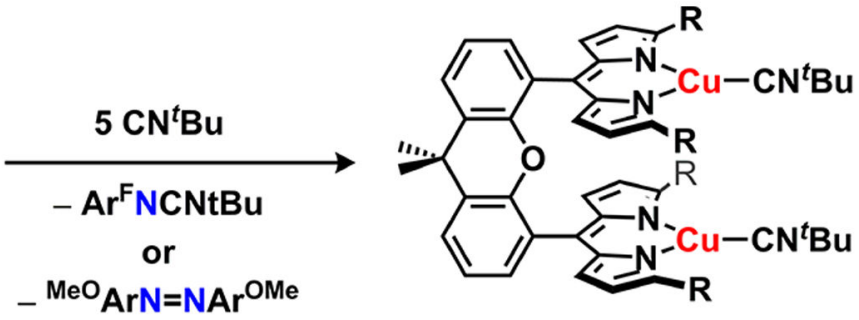

Mes (14); ${ }^{t} \mathrm{Bu},(15)$ 


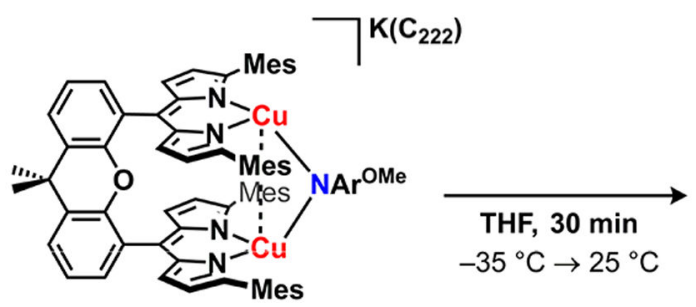

(7)

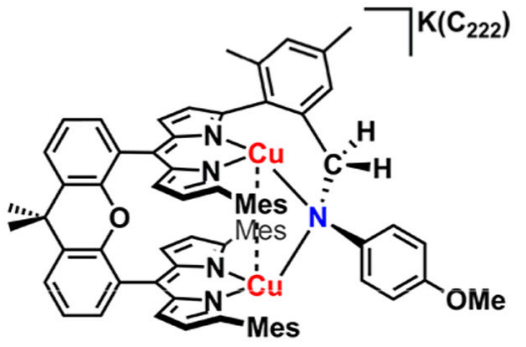

(17)

Scheme 7 


\section{을 \\ }

로을

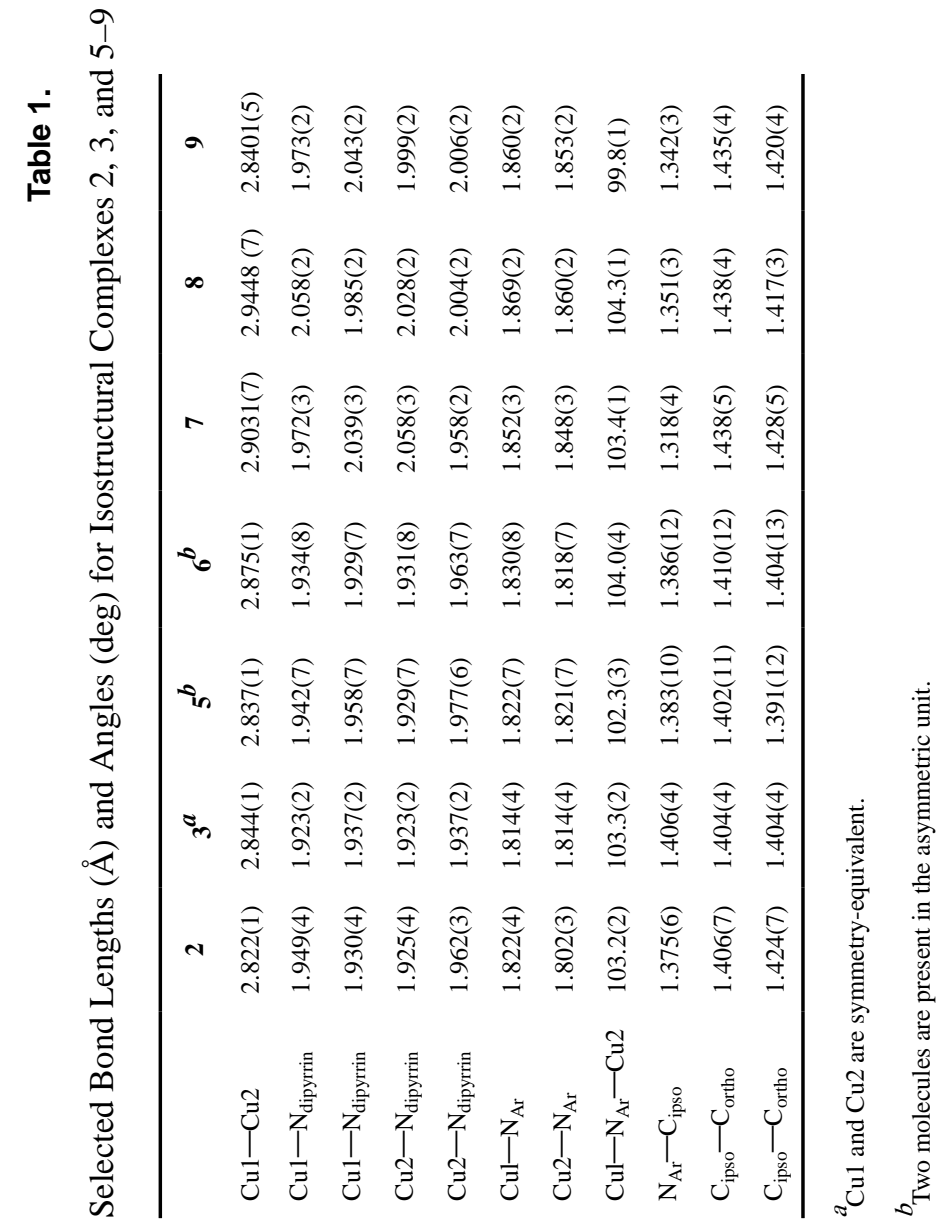

J Am Chem Soc. Author manuscript; available in PMC 2020 June 01. 